\title{
Low heat joining - manufacturing and fatigue strength of brazed, locally hardened structures
}

\author{
Volker Wesling ${ }^{1, a}$, Antonia Schram ${ }^{1, b}$, Mirjam Kessler ${ }^{1, c}$ \\ ${ }^{1}$ Institute of Welding and Machining (ISAF), Clausthal University of Technology (TUC), \\ Agricolastr. 2, 38678 Clausthal-Zellerfeld, Germany \\ a office@isaf.tu-clausthal.de, ${ }^{b}$ Schram@isaf.tu-clausthal.de, ${ }^{c}$ Kessler@isaf.tu-clausthal.de
}

\begin{abstract}
Keywords: Low heat joining, arc brazing, plasma brazing, advanced high strength steel, locally hardened structure, fatigue strength
\end{abstract}

\begin{abstract}
Low-heat brazing as a joining option for high strength steel sheets under cyclic load is still a challenge for manufacturing. For application arc brazing to locally hardened, high strength steel sheets a material specific manufacturing concept is needed to ensure a quality-related, reliable and reproducible processing. Thus the interaction of brazing parameters, metallurgical properties, types of brazed seams and different arc-processes under cyclic load were investigated. This should extinguish the base for an extended application of arc-brazed joints at cyclic loaded, high strength, property adjusted structures.
\end{abstract}

\section{Introduction}

Nowadays the interest in joining metal sheets by low-heat methods like adhesives, clinching and brazing remarkably increases. Especially the application of automated brazing processes and the development of new brazing fillers and process methods have resulted in an ongoing increase of the importance of brazing as a joining option [1-3]. Due to its flexibility hard-brazing has become an important alternative to common metal-arc-welding (MAW) processes in modern manufacturing. It can be regarded as a promising and cost-effective joining process for the fields of automotive and aerospace, energy, and logistics. The advantages of hard-brazing include corrosion resistance, low distortion, and over all local material properties are hardly influenced, due to the low heat input. As a result the brazing process is appropriate for joining heat-sensitive and locally hardened structures $[4,5]$. These materials pass through a complex manufacturing process to get their locally defined properties. They can be easily destroyed in case of heat exposure (e.g. martensite formation, local softening and others). As a consequence of the low heat process these complex characteristics are just limited affected. As a hard brazing process recently arc brazing is the most demanded for joining high strength and dynamical loaded structures [6-9].

Deficits which have prevented the widespread use of brazed high-strength structures and nodes are associated especially with the reliability of the brazed joint. There is a lack of understanding the interaction of the brazing parameters, the geometry of the brazed seam, and the brazing filler regarding of reliability and reproducibility. Indeed these factors are not the only challenges for the use of brazed joints but there is also an immense divergence of the strength between locally hardened high strength steels, used in this project, and the applied copper-based filler. Mainly hardbrazed joints are qualified by static strength - tensile test - but normally not by fatigue testings. Fatigue strength is detected as add on at the end of investigations [4]. In particular, the behaviour of brazed structures of materials with locally altered properties under alternating stress cannot be appraised with conventional methods. Consequently, so far it has not been possible to predict the lifetime of brazed structures and nodes under alternating stress. To increase the strength of brazed high-strength structures, which acquire their structural properties from locally adapted material properties (locally hardened materials), the properties of the component can be influenced by controlling the geometrical effect on the brazed joint and by application related selection of the 
filler properties. In this context, the structural properties under alternating stress are of special importance [10].

The aim of the following investigations was to find out quality-related brazing parameters for surface-coated, high-strength steel sheets and to detect their influence on the cyclic strength. These investigations should extinguish the base for an extended application of hard-brazed joints at cyclic loaded, high-strength, property adjusted structures.

Within these studies investigations were carried out to demonstrate the influence of:

- different metallurgical properties

- different copper-based fillers

- different types of shielding gases

- different types of brazed-seam

- different hard-brazing processes

- the influence of the process heat

- the effect of post-treatment

\section{Experimental procedure}

Arc-brazing processes are used because of their high flexibility and wide process window. It has been applied especially for joining sheet-metals; however, it is also a promising method for joining structures of high strength materials with locally modified properties, appreciably because the low heat input does not affect the material strength. For the realisation of a low-heat brazing, innovative process- modes of arc-brazing were used.

Different dual phase steel sheets from two manufacturers were investigated to qualify the arc processes for locally hardened structures. The assortment of steel sheets was chosen because of their micro-structures. These steels have a defined set up structure by means of a thermomechanical treatment which is sensitive for heat and therefore comparable in its complex joining requirements to those materials and structures adjusted properties manufactured in the context of the SFB675.

Arc brazing - CMT-process. Initiating a variance of the metal arc process (MAB) was used, more specifically of the short arc mode, the cold-metal-transfer-process (CMT). This process has a special controlling system with a directly integrated wire movement. Therefore this method allows reducing the energy per length brazed and at the same time it is more reliable compared to common MA-brazing-processes.

The differentiation of the CMT-process from common MAB-processes are:

- Characteristically the CMT-process controls the current within the short circuit to a low level for reducing the heat input

- For enabling the releasing of liquid filler material the wire is not just moved translative as in common processes but as well in an oscillating mode, cp. Fig. 1.
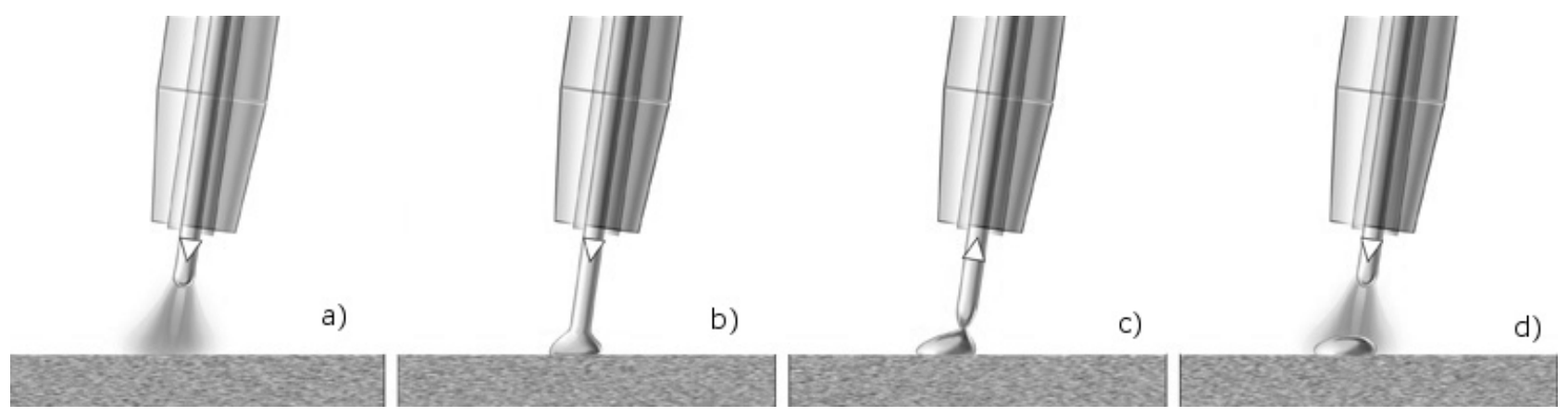

Fig. 1: CMT (cold metal transfer) process [11] 
The drop release occurs in the short arc range as a result of controlled wire feed, Fig. 1b. Reverse motion of the wire supports the drop transfer, which takes place at a current of about zero, Fig. 1c). Thus, the material is transferred at low temperature, compared to the conventional MAB-process. Additional this procedure runs up to 70 times per second. Because of the mechanical control and adjustment of the arc length, it is independent of the surface of the work piece and the brazing speed. It has been shown that the process is well suited especially for arc brazing. In particular, the process is almost scab-free; consequently, mechanical finishing of the seam is not necessary [11].

The test rig used for the brazing studies is shown in Fig. 2a. The used system is the TPS 4000 CMT with the control-panel RCU 5000i, and the wire-feeder VR7000 by Fronius. In Fig. $2 \mathrm{~b}$ the arrangement of blowpipe and clamping piece is shown.

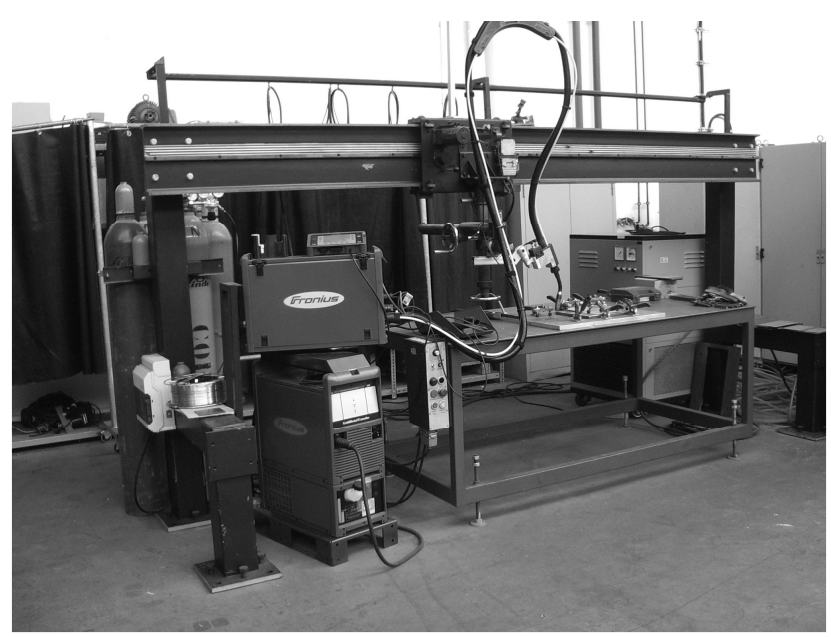

a) Test rig with traverse positioning table

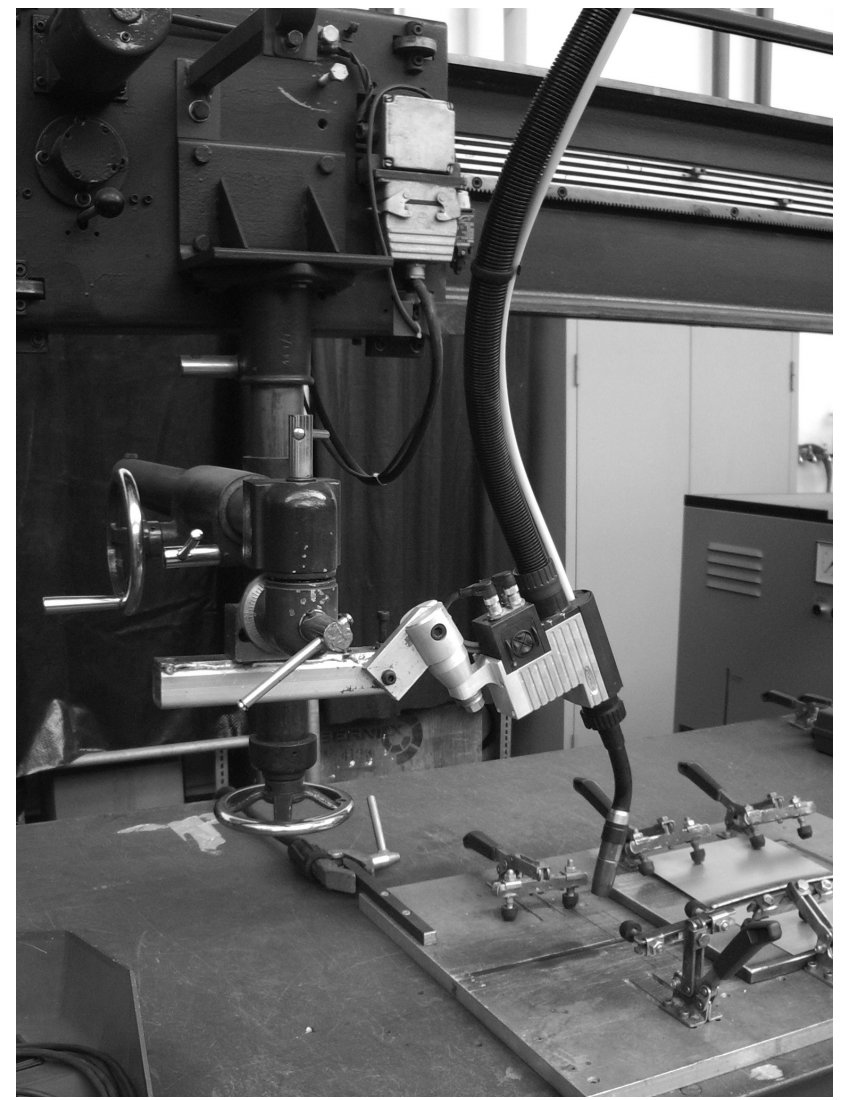

b) Blow-pipe and clamping piece

Fig. 2: CMT test rig, ISAF

Plasma brazing - Plasmatron-process. The second arc brazing process used is a special modification of the plasma arc brazing process, the Plasmatron process. Unique at this plasmabrazing-method is that the ignition of plasma takes place outside the nozzle. The brazing torch construction differs from common plasma systems; cp. Fig. 3a, the tungsten electrode sticks out of the nozzle and therefore overleaping of the arc is prevented. A slim scale of the torch can be realised because the plasma is not generated by a plasma-nozzle but by a shielding gas, cp. Fig. $3 \mathrm{~b}$. The gas constricts the arc until a plasma occurs. Additional there is only one type of gas in use and not as usual a shielding and a plasma gas [12]. Therefore the slim scale of the torch allows overhead brazing and brazing in narrow gaps, which is impossible with common blow-pipe designs. 


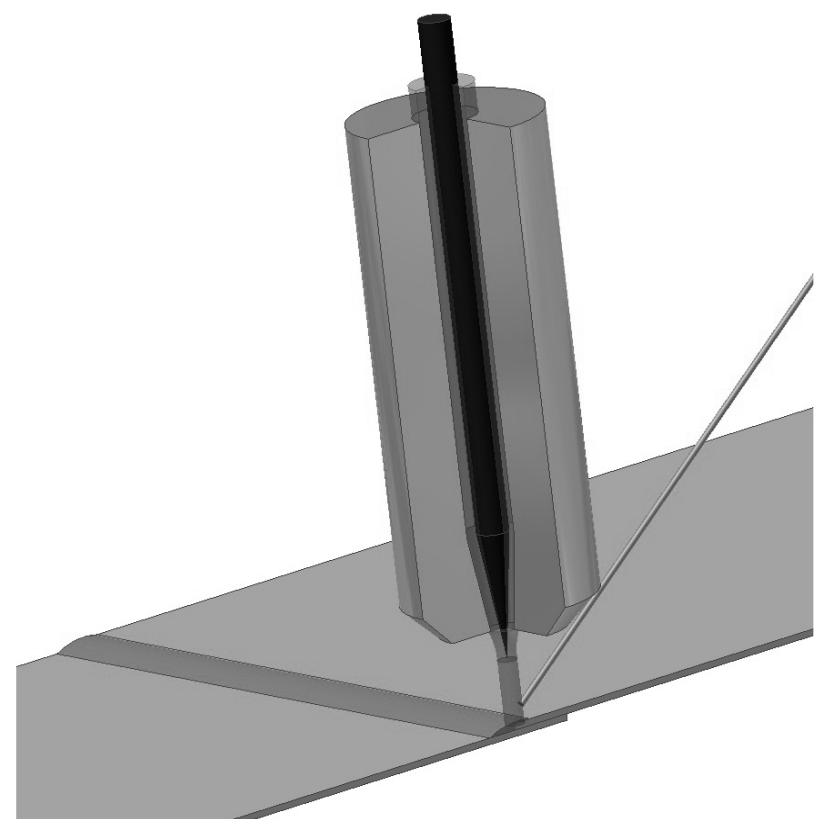

a) Draft of Plasmatron process with additional wire feed

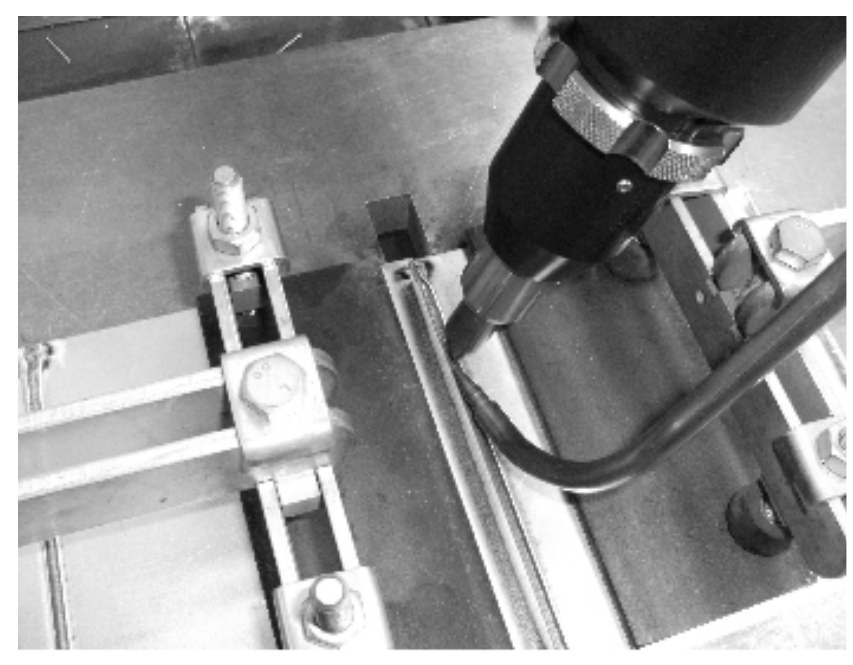

b) Plasmatron blow-pipe and clamping piece

Fig. 3: Plasmatron process

The advantage of the Plasmatron process in comparison to conventional ones is the beneficial in purchase and the increased electrode-endurance. This process can be operated robotically as well as manually. Furthermore it is possible to decouple the strength of current and the rate of the wire feeder. Therefore a low heat input is enabled and as a consequence this process is advantageous for the research-project.

The used system is a combination of the Magic Wave 2200 by Fronius and the Plasmatron-blowpipe by Inocon. Fig. $3 b$ shows the arrangement of blowpipe including wire feed and clamping piece.

Base material. For the first period of the experiments two grades of high-strength cold-rolled dual-phase steel sheets were chosen. The dual-phase steel represents a type of steel which meets the requirements of a heat-sensitive and high strength material with severe demands for their local metallurgical characteristics.

Dual-phase steels are hypo-eutectoid with a carbon content of about $0.02-0.23 \mathrm{wt} \%$. By means of a special annealing process the micro-structure is a mixture of ferritic and martensitic components, cp. Fig. 4 and 5. Thereby the hard martensitic phases (dark grey) are embedded in a flexible ferrite-matrix (light grey) and because of this strengthening is achieved. Due to the quite low amount of martensite in the structure (less than 30\%) they also have a good deformability behaviour. All these properties are also required for the local strengthened structures, as manufactured within the SFB675. All tested dual-phase steel sheets have a dip coating of zinc, with a firing temperature of $900^{\circ} \mathrm{C}$, and therefore this coating is easily burnt during joining processes $[13,14]$.

The mechanical properties and the chemical composition of the steel grades used are shown in Table 1 to 3 . 
Table 1: Mechanical properties; manufacturer's instruction

\begin{tabular}{|c|c|c|c|c|}
\hline material & $\begin{array}{c}\text { yield strength } \\
\mathrm{R}_{\mathrm{p} 0,2} \\
{[\mathrm{MPa}]}\end{array}$ & $\begin{array}{c}\text { ultimate tensile } \\
\text { strength } \\
\mathrm{R}_{\mathrm{m}} \\
{[\mathrm{MPa}]}\end{array}$ & $\begin{array}{c}\text { strain at failure } \\
\mathrm{A}_{80} \\
{[\%]}\end{array}$ & $\begin{array}{c}\text { bake hardening } \\
\mathrm{BH}_{2} \\
{[\mathrm{MPa}]}\end{array}$ \\
\hline $\begin{array}{c}\text { HCT600XD } \\
\text { (Thyssen Steel } \\
\text { Europe AG) }\end{array}$ & $340-420$ & $>600$ & $>20$ & 30 \\
\hline $\begin{array}{c}\text { HCT780XD } \\
\text { (Salzgitter } \\
\text { Mannesmann } \\
\text { Forschung } \\
\text { GmbH) }\end{array}$ & $450-560$ & $>780$ & $>14$ & 30 \\
\hline
\end{tabular}

Table 2: Chemical composition of HCT600XD, optical emission spectroscopy, [wt\%]

\begin{tabular}{|c|c|c|c|c|c|c|c|}
\hline $\mathbf{C}$ & $\mathbf{S i}$ & $\mathbf{M n}$ & $\mathbf{M o}$ & $\mathbf{C r}$ & $\mathbf{N i}$ & $\mathbf{N b}$ & $\mathbf{T i}$ \\
\hline 0.1448 & 0.2342 & 1.8450 & 0.0026 & 0.3802 & 0.0425 & 0.0040 & 0.0400 \\
\hline $\mathbf{A l}$ & $\mathbf{V}$ & $\mathbf{W}$ & $\mathbf{C o}$ & $\mathbf{C u}$ & $\mathbf{B}$ & $\mathbf{P}$ & $\mathbf{S}$ \\
\hline 0.3007 & 0.0010 & 0.8190 & 0.0100 & 0.0558 & 0.0003 & 0.0059 & 0.0054 \\
\hline $\mathbf{P b}$ & $\mathbf{N}$ & $\mathbf{S n}$ & $\mathbf{A s}$ & & & & \\
\hline 0.0020 & 0.0484 & 0.0010 & 0.0010 & & & & \\
\hline
\end{tabular}

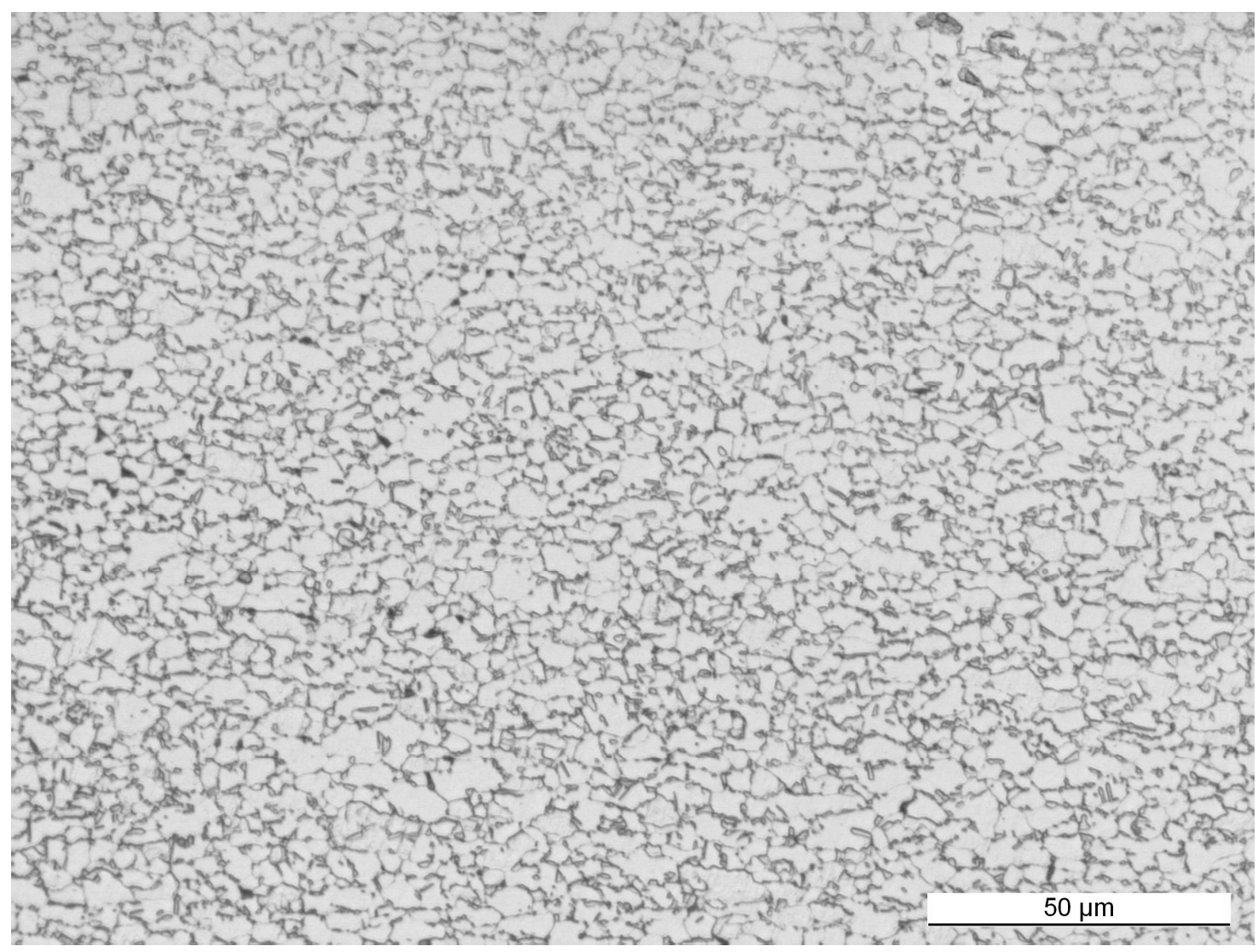

Fig. 4: Micro-structure of HCT600XD, low rate of martensite; scale: $50 \mu \mathrm{m}$ 
Table 3: Chemical composition of HCT780XD, optical emission spectroscopy, [wt\%]

\begin{tabular}{|c|c|c|c|c|c|c|c|}
\hline $\mathbf{C}$ & $\mathbf{S i}$ & $\mathbf{M n}$ & $\mathbf{M o}$ & $\mathbf{C r}$ & $\mathbf{N i}$ & $\mathbf{N b}$ & $\mathbf{T i}$ \\
\hline 0.1256 & 0.0452 & 1.836 & 0.02 & 0.31 & 0.0240 & 0.0084 & 0.0031 \\
\hline $\mathbf{A l}$ & $\mathbf{V}$ & $\mathbf{W}$ & $\mathbf{C o}$ & $\mathbf{C u}$ & $\mathbf{B}$ & $\mathbf{P}$ & $\mathbf{S}$ \\
\hline 1.23 & 0.03 & $<0.0100$ & 0.01 & 0.0162 & 0 & 0.0181 & $<0.002$ \\
\hline $\mathbf{P b}$ & $\mathbf{N}$ & $\mathbf{S n}$ & $\mathbf{A s}$ & & & & \\
\hline$<0.002$ & 0.0037 & 0.0058 & 0.0058 & & & & \\
\hline
\end{tabular}

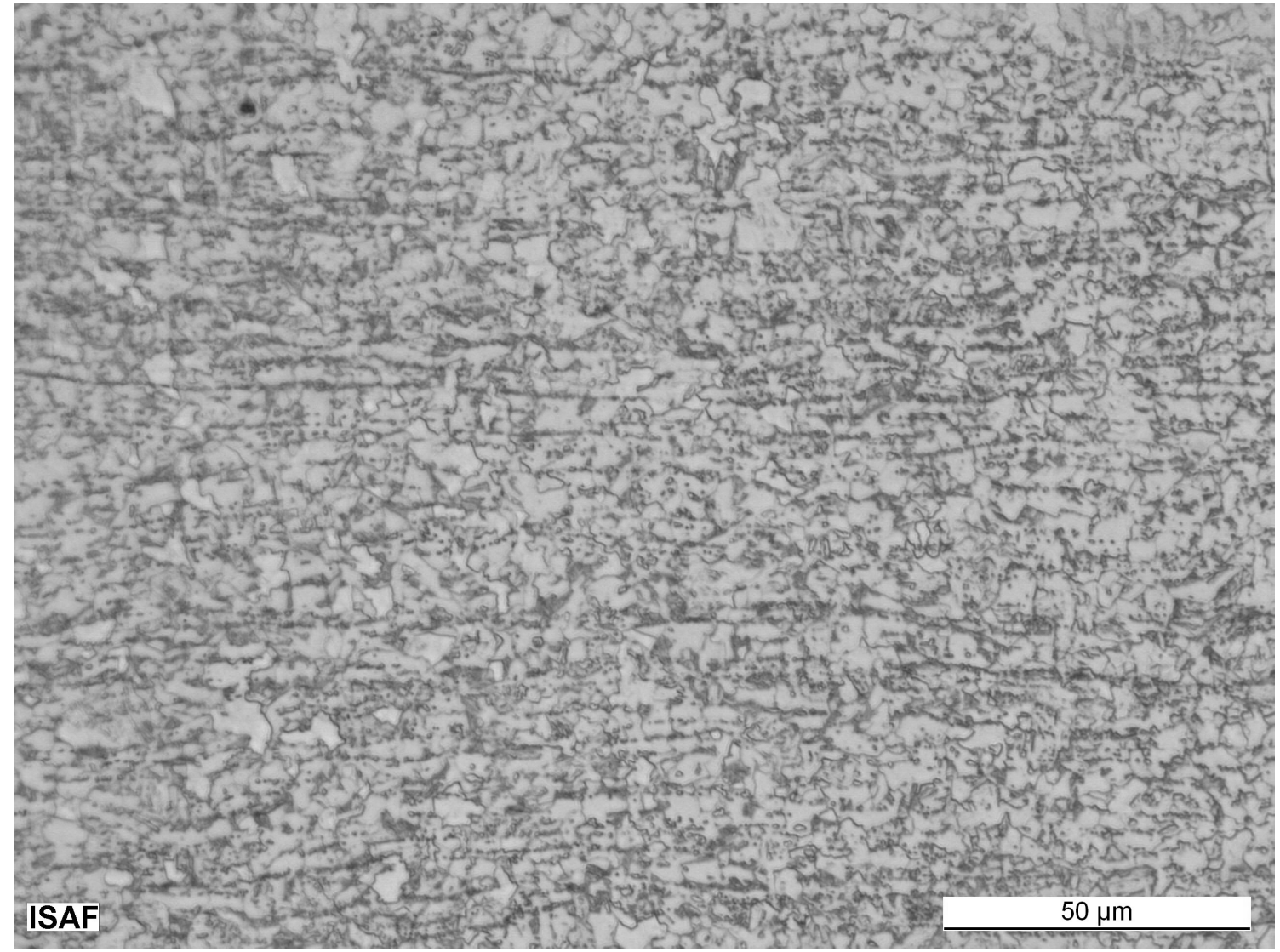

Fig. 5: Micro-structure of HCT780XD, high rate of martensite; scale: $50 \mu \mathrm{m}$

Brazing fillers. Copper-based fillers were used for the investigations. This filler material is commonly used for arc brazing processes. They are advantageous because of their high corrosion resistance, why there is no need to apply a protective coating to the brazed joints afterwards.

As a matter of principle, it must be remembered that the strength of the brazing filler is lower compared to the base metal, when higher-strength and high-strength steels are joined with copperbased fillers, [5, 9]. Applied fillers including their mechanical properties are shown in Table 4.

The heat affected zone (HAZ) of a brazed seam is shown in Fig. 6. At the boundary between the base material and the filler a narrow zone of alloy evolves. The HAZ extends over the complete seam and ends directly at the crossing of brazed filler and base material. 
Table 4: Applied brazing fillers, by manufacturer's instruction

\begin{tabular}{|c|c|c|c|c|}
\hline & material number & $\begin{array}{c}\text { melting range } \\
{\left[{ }^{\circ} \mathrm{C}\right]}\end{array}$ & $\begin{array}{c}\text { ultimate tensile } \\
\text { strength } \mathrm{R}_{\mathrm{m}} \\
{[\mathrm{MPa}]}\end{array}$ & $\begin{array}{c}\text { yield strength } \\
\mathrm{R}_{\mathrm{p} 0.2} \\
{[\mathrm{MPa}]}\end{array}$ \\
\hline $\mathrm{CuSi3Mn1}$ & 2.1461 & $910-1025$ & $340-460$ & $>120$ \\
\hline $\mathrm{CuAl7}$ & 2.0921 & $1030-1040$ & $380-450$ & 180 \\
\hline $\mathrm{CuSn} 6+\mathrm{P}$ & 2.1020 & $910-1040$ & $>260$ & $>150$ \\
\hline
\end{tabular}

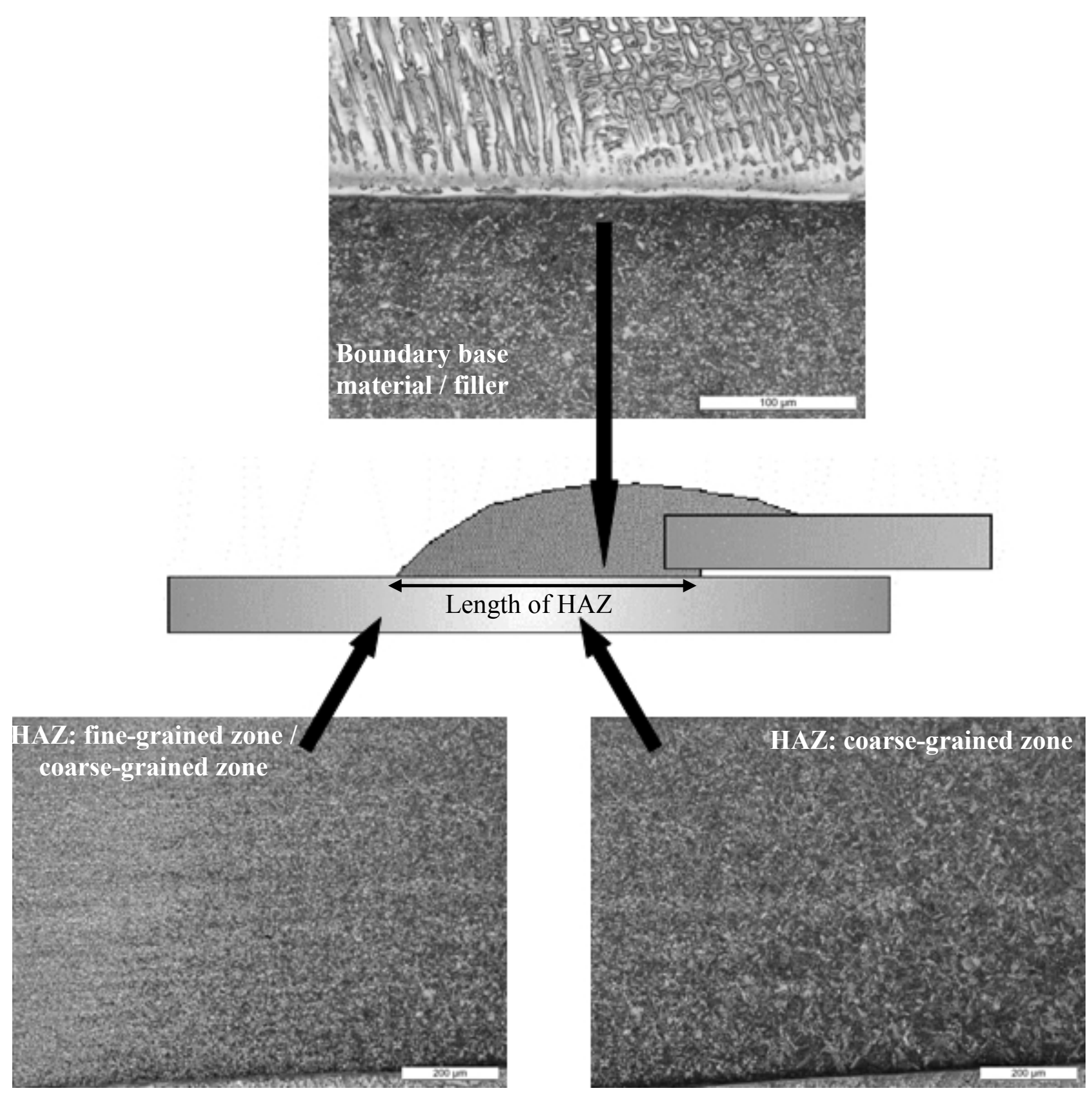

Fig. 6: Overview of a brazed joint and its heat-affected-zone (HAZ); HCT600XD, CuSi3Mn1; scale 100 and $200 \mu \mathrm{m}$ 
Test parameters. The brazed joints were accomplished on steel sheets, HCT600XD+ZE with a thickness of $0.8 \mathrm{~mm}$ and HCT780XD+ZE with a thickness of $0.9 \mathrm{~mm}$. The testing sheets had a dimension of $145 \mathrm{~mm} \times 140 \mathrm{~mm}$ and were cut perpendicular to the rolling-direction in order to have comparable and uniform properties of the base material. Before brazing all sheets were pretreated with ethanol for reducing the influence of surface contamination and accomplish a joint without imperfections and a steady process.

The prepared sheets were clamped on the workbench, see Fig. 2 and 3. All sheets were realised with a fillet brazed at a lap joint, overlap of $10 \mathrm{~mm}$, and a technical brazing gap of zero.

The brazed joints were accomplished as unilateral as well as bilateral joints. All further constant brazing parameters can be extracted of Table 5. These are the result of qualifying studies at the beginning of the research-project.

Table 5: Constant brazing parameters

\begin{tabular}{|l|l|}
\hline brazing position & PA \\
\hline amount of shielding gas $[1 / \mathrm{min}]$ & $12(\mathrm{CMT}) ; 4-6$ (Plasmatron) \\
\hline bearing corner radius $[\mathrm{mm}]$ & 0.5 \\
\hline diameter of brazing wire $[\mathrm{mm}]$ & $1.0(\mathrm{CMT}) ; 1.0$ and 1.6 (Plasmatron) \\
\hline brazing speed $[\mathrm{m} / \mathrm{min}]$ & 1.0 \\
\hline pitch $\left[^{\circ}\right]$ & $90(\mathrm{CMT}) ;$ Plasmatron varied \\
\hline sort of shielding gas & ArHe30 (Plasmatron); CMT varied \\
\hline
\end{tabular}

Besides the qualifying studies for constant brazing parameters also studies on the influence of shielding gases on process stability, phenotype of the brazed seam and fatigue strength were carried out. This qualification was done with the CMT-process. For investigations the following compositions of shielding gases were used:

- inert gases: $70 \% \mathrm{Ar}+30 \% \mathrm{He}$

$$
\begin{aligned}
& 60 \% \mathrm{Ar}+40 \% \mathrm{He} \\
& 95 \% \mathrm{Ar}+5 \% \mathrm{He}
\end{aligned}
$$

- active gases: $63 \% \mathrm{Ar}+30 \% \mathrm{He}+7 \% \mathrm{H}_{2}$

$$
\begin{aligned}
& 97.5 \% \mathrm{Ar}+2.5 \% \mathrm{CO}_{2} \\
& 99 \% \mathrm{Ar}+1 \% \mathrm{O}_{2} \\
& 90 \% \mathrm{Ar}+10 \% \mathrm{H}_{2} \\
& 97.97 \% \mathrm{Ar}+2 \% \mathrm{CO}_{2}+0.03 \% \mathrm{NO}
\end{aligned}
$$

The fatigue testings were carried out using resonance testers of Roell/Amsler (stress ratio $\mathrm{R}=0$ ) and Instron 1603 (stress ratio $\mathrm{R}=0.1$ ) equipped with a $20 \mathrm{kN}$ load-cell. All specimens were loaded axially with a pulsating load. The testings were evaluated by alternating one sample per tension level and as result S-N-curves were plotted and the k-factors (slope of the regression line) were determined. For tensile testing the electro-mechanical tester RSA 100 by Schenck-Trebel was used.

\section{Results and discussion}

Subsequently the procedure is shown for brazing with optimised macro geometry of the seam with variation of brazing-process, brazing-system, and the seam geometry. All tests are evaluated on the improvement of the manufacturing process regarding reliability, reproducibility, and fatigue strength (cyclic load) of the joints. 
Influence of shielding gases. In the first instance investigations on joining HCT600XD (0.8 mm) with the CMT-process were made. First of all the fundamental influences on the different process parameters were investigated:

- bearing corner - distance of wire to edge of upper sheet

- blowpipe guidance - setting angle and brazing positions

- amount of shielding gas

These factors have a severe effect on the reliability and the reproducibility of the joining process. The results of the studies are used as constant parameters for ongoing manufacturing of brazedsamples.

In order to achieve a modified geometry of brazed seams and as a consequence for advanced attributes of the brazed connection, different shielding gases with varying composition, cp. "test parameters", were used. The composition mainly influences the viscosity of the melting bath and thereby the formation of the brazed seam. Additionally the porosity of the seam is affected, see Fig. 7. The seam brazed with hydrogen had a much higher porosity compared to the one brazed with carbon dioxide.

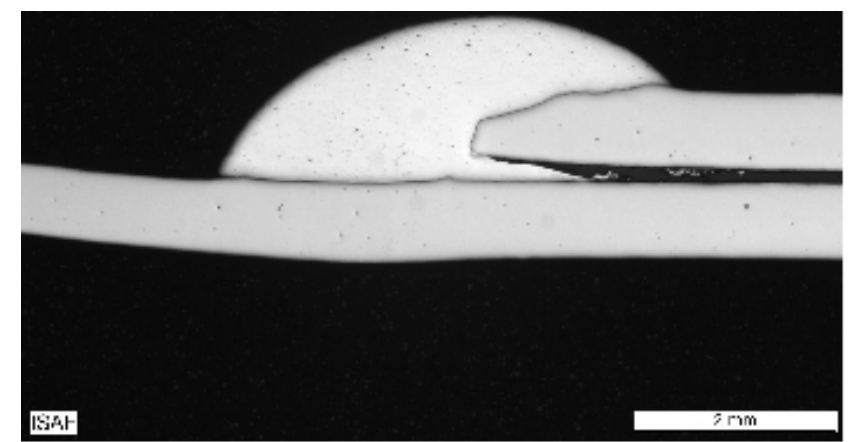

a) $\mathrm{CuSi} 3 ; \mathrm{ArCO}_{2} 2,5 \%$; bilateral brazed

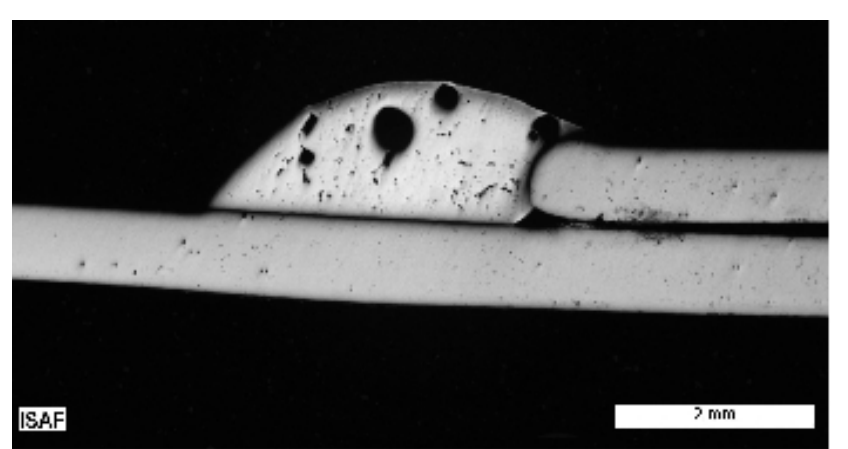

b) $\mathrm{CuSi} 3 ; \mathrm{ArH}_{2} 10 \%$; bilateral brazed

Fig. 7: Influence of the shielding gas on the macro structure of the brazed seams; scale: $2 \mathrm{~mm}$

This result is also illustrated in the tensile strength, cp. Fig. 8. The static strength of the optical imperfection free seam achieves the strength of the base material, due to the higher stiffness of the bilateral seam and the good adhesion. The seam brazed with $\mathrm{ArH}_{2} 10 \%$ has two third of the mechanical resistance because the voids weaken the cross section and as a consequence they interfere the flux of forces. Certainly the results of the cyclic testing show up a quite divergent characteristic, Fig. 9. The cyclic strength of the optical imperfection free seams, Fig. 7a, is lightly under the compared sample with voids, Fig. 7b, as well they are positioned at the same scatter band. Although the scattering of the $\mathrm{ArH}_{2} 10 \%$-brazed specimens is larger the effect on the strength is not comparable to the static-test-result. This behaviour is due to the reduced heat exposure by using $\mathrm{H}_{2}$ as a component of the shielding-gas. The application leads to a concentrating of the arc and therefore less energy is needed for the brazing process. 


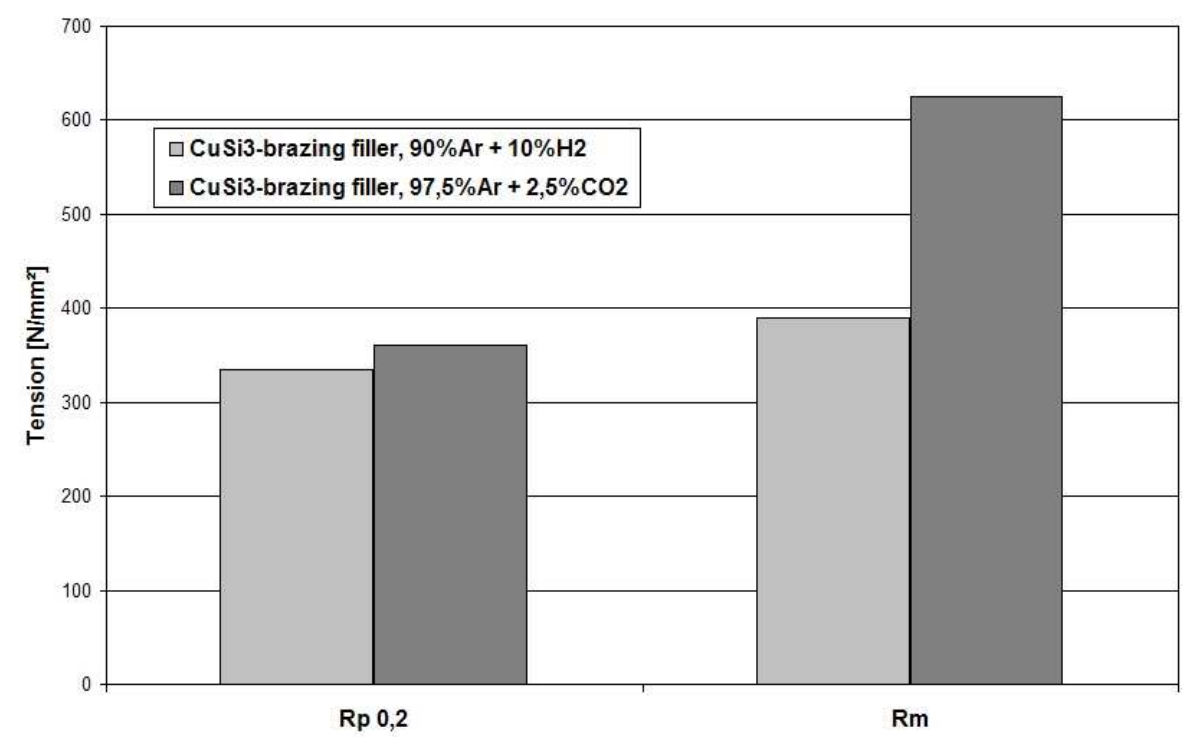

Fig. 8: Tensile strength of bilateral brazed joins, HCT600XD, CuSi3Mn1

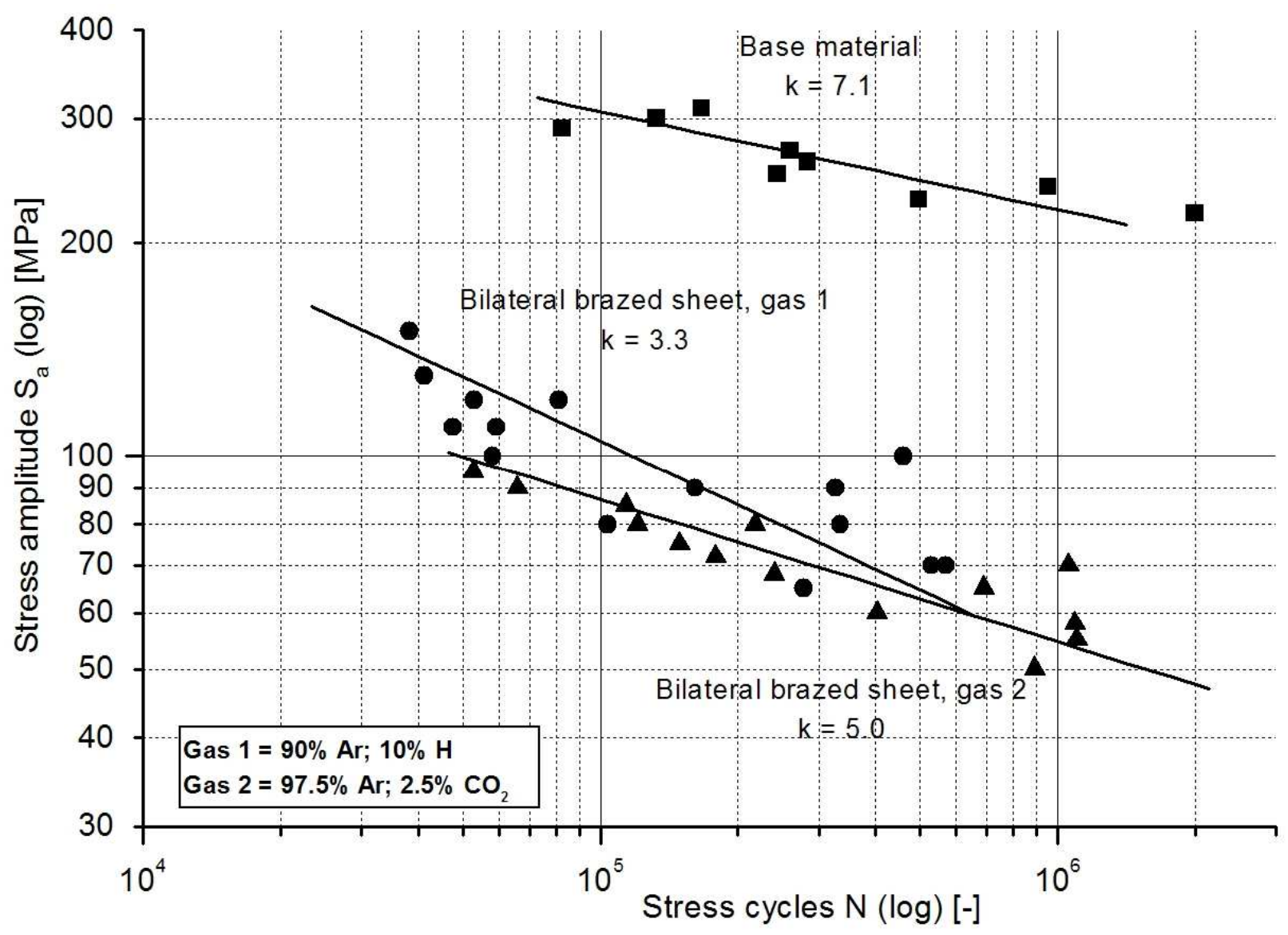

Fig. 9: Influence of shielding gas on the cyclic strength, HCT600XD, CuSi3Mn1, R=0

This result already shows up, that a qualification of brazed joints and process control by quasi-static tensile tests and random fatigue testings is not suitable for a reliable manufacturing strategy. As a consequence there has to be a distinction of the application under static and cyclic stress.

Influence of process control - geometrical notch. The continuative studies were partly accomplished with the second steel grade, HCT780XD, in order to indicate different influences of the structure of the base material and extended the manufacturing strategy for locally hardened 
structures. Low-heat-joining of the higher strengthened steel extinguishes a bigger challenge due to the mechanical and metallurgical properties of these materials.

The influence on the appearance of the seam was expanded by a variety of seam build up. It was the aim to achieve a geometry with a long connection and a small contact angle and thus reducing the geometrical notch effect. There had been examination on:

- double-coated and three-coated seams; TIG-remelted

- weaved seam; sheet thickness $1.6 \mathrm{~mm}$

- mechanical reduction of brazed seam (approximation to the flux of forces)

- unilateral and bilateral lap joints

The varieties of TIG-remelting and weaving cause a seam which is geometrically desirable; see Fig. 10a, but the higher energy input into the base material leads to severe problems. These brazed sheets were deformed and because of heat-exposure the micro-structure of the dual phase steel was affected in a large amount by martensite evolution. Further on the high joining energy lead to a larger-scaled burning of the zinc-coating.

The mechanical reduction of the seam did not affect the cyclic strength because it has been impossible to reduce the notch in an appropriate amount without penetrating the base material, Fig. 10b.

Contrary to the previous results the cyclic strength of bilateral seams could be increased by $55 \%$, Fig. 11, due to their higher stiffness and the doubled connection length. Besides, two sided seamed specimens are not stressed multi-axial during the alternating stress.

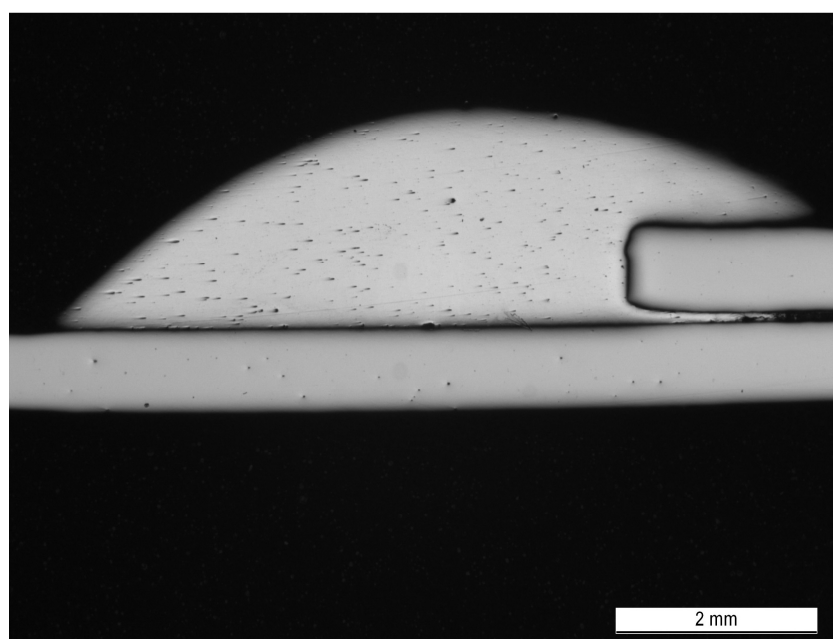

a) weaved seam; sheet thickness $1.6 \mathrm{~mm}$

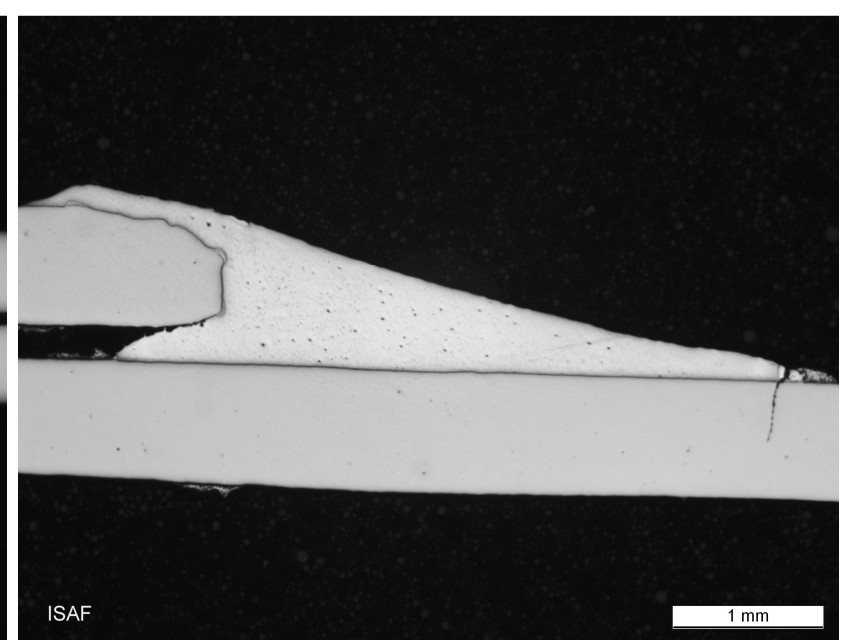

b) mechanical reduced brazed seam, after alternating

Fig. 10: Examples of different form of seams, scale: $2 \mathrm{~mm}$ and $1 \mathrm{~mm}$ 


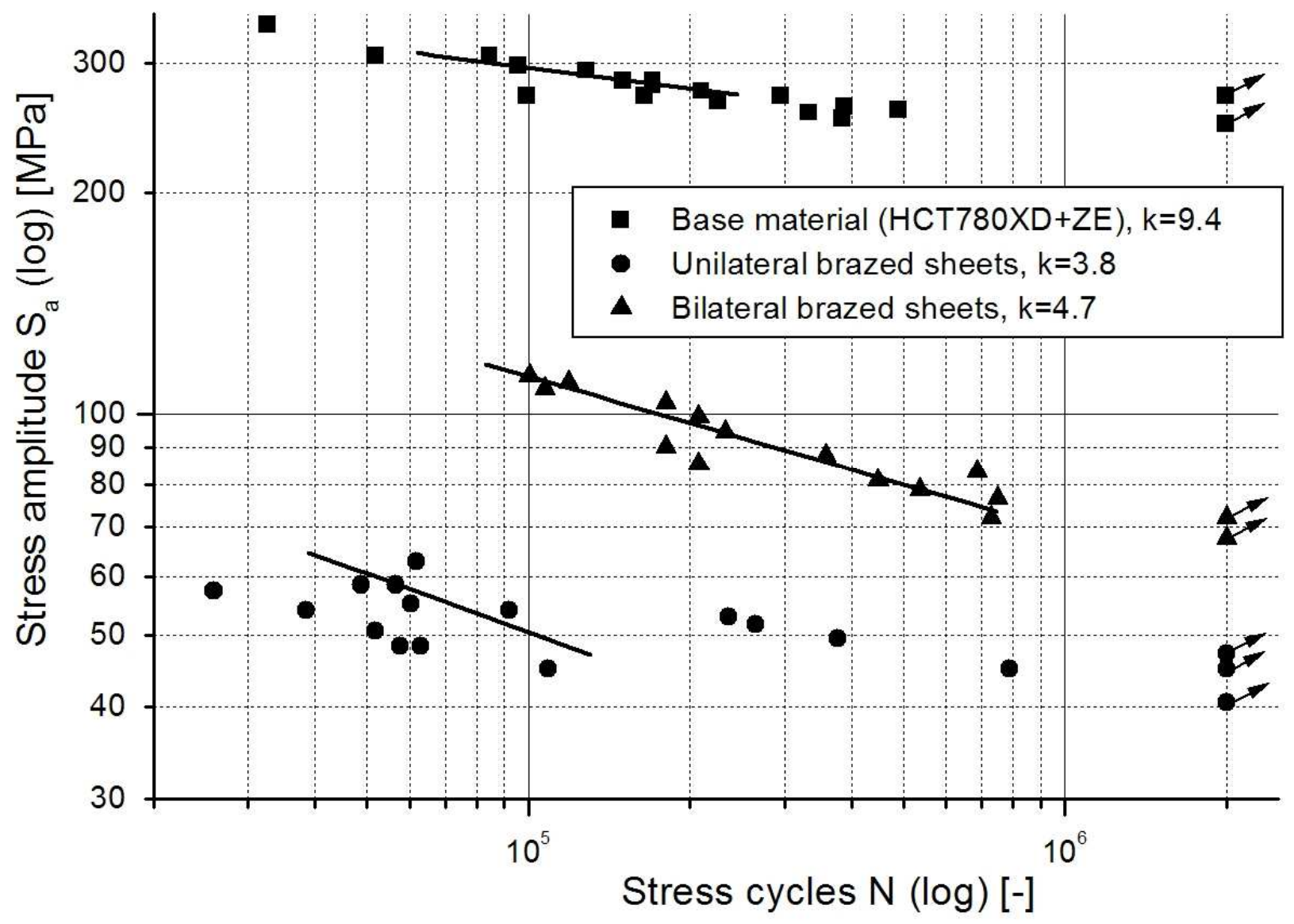

Fig. 11: S-N-curve - comparison of cyclic strength of unilateral and bilateral seam, $\operatorname{ArHe}(30 \%)$, HCT780XD, CuSn6+P, R=0.1

On the other side the usage of a double-sided fillet increases the effort for manufacturing, although the increase of the fatigue strength is not doubled. Further on, realising bilateral brazed structures is sometimes impossible because of the accessibility.

Influence of heat input - metallurgical notch. For determination the influence of the heat input in heat sensitive materials, as used for the studies, on the cyclic load capacity, studies were made with different rates of wire feeder. Specific for all MAB-processes, including the CMT-variant, is that they can only be controlled by the wire feeding-rate; the more wire is required the higher is the energy needed to melt the filler and therefore the heat which effects the base metal. To determine the heat influence, three different rates of wire-feeder were investigated, Table 6.

The first result is that there is a metallurgical notch right at the boundary of the brazed-seam and the base material, Fig. 12, leading to softening of the structure.

Table 6: Rate of wire feeder

\begin{tabular}{|l|l|l|}
\hline $\mathrm{v}_{\mathrm{W}}=2.8 \mathrm{~m} / \mathrm{min}$ & $\mathrm{v}_{\mathrm{w}}=3.2 \mathrm{~m} / \mathrm{min}$ & $\mathrm{v}_{\mathrm{w}}=3.5 \mathrm{~m} / \mathrm{min}$ \\
\hline
\end{tabular}




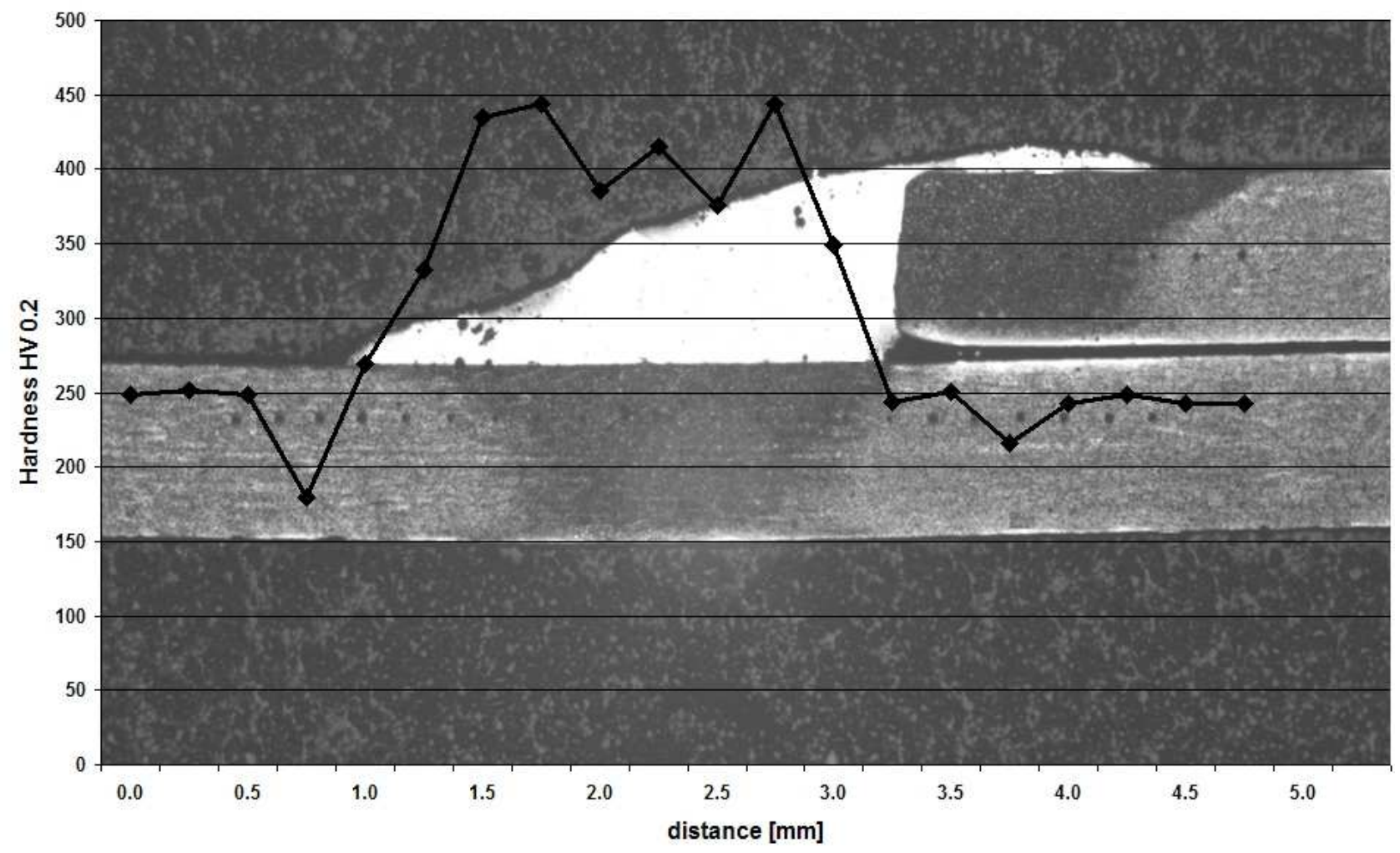

Fig. 12: Hardness continuum of an unilateral brazed joint, $\mathrm{v}_{\mathrm{w}}=2.8 \mathrm{~m} / \mathrm{min}, \mathrm{HCT} 780 \mathrm{XD}, \mathrm{CuSn} 6+\mathrm{P}$

Most commonly the break of the sample occurs at this location under cyclic load. The samples crack directly at the cross-over of the three notches - metallurgical, geometrical, and the change in stiffness, cp. Fig. 13.

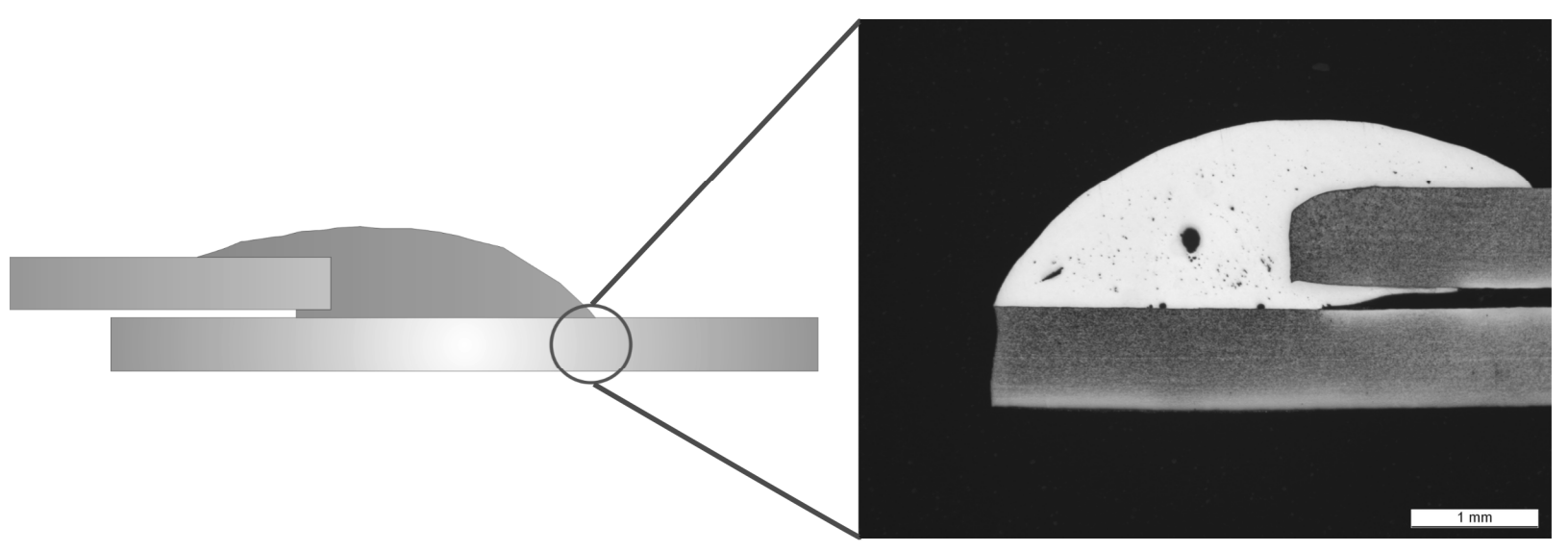

Fig. 13: Failure locations under cyclic loading; scale: $1 \mathrm{~mm}$ 


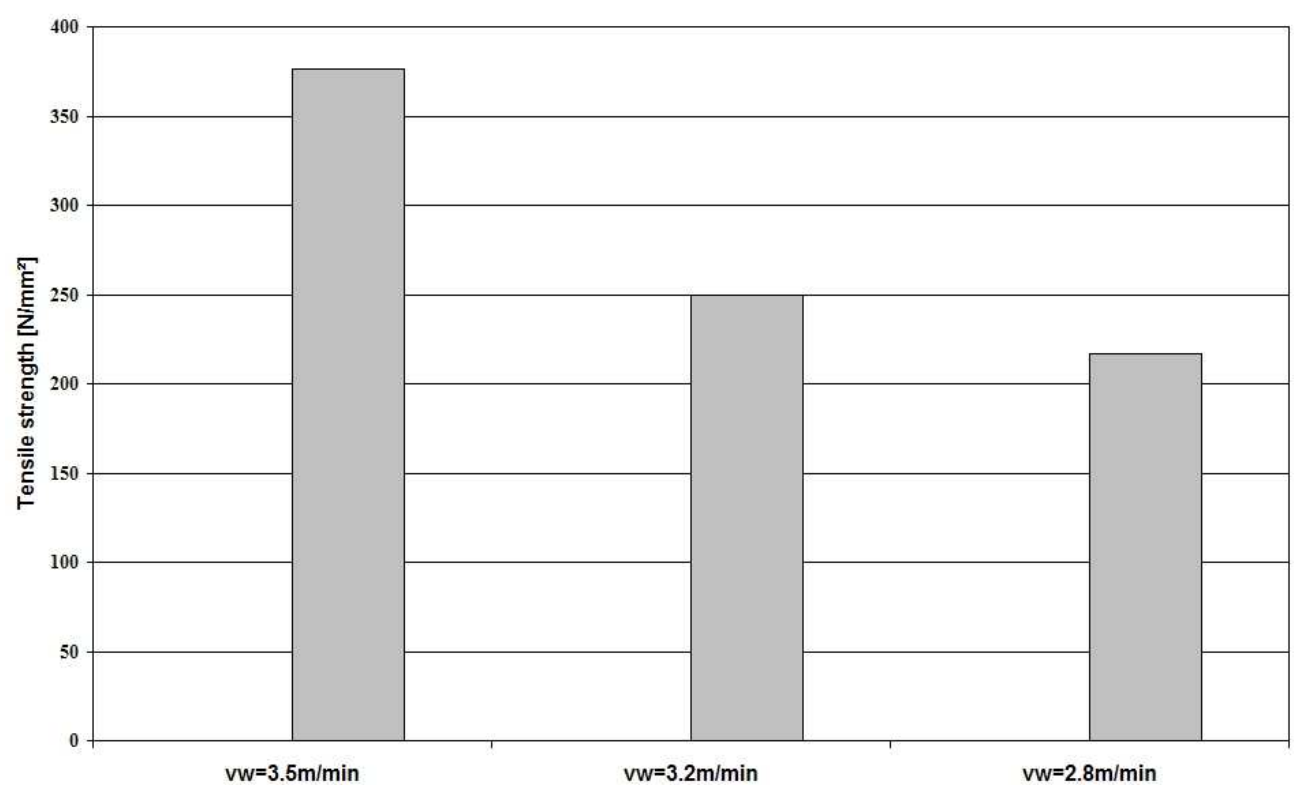

Fig. 14: Tensile strength of unilateral brazed joints, different rates of wire feeder, HCT780XD, CuSn6+P

As shown in Fig. 14 an increase of the wire-rate is beneficial for the tensile strength, which is up to $75 \%$ above the strength of the specimen, brazed with the lower energy, although the failure location was the brazed seam for all specimens. This is based on the extended time for diffusion, the increased viscosity, the better release of gas, and a more steady process. In contrast the increased rate of wire-feeder leads to a climax of the energy input, and to increased distortion of the structure. This is disadvantageous in case of the preservation of locally hardened structures and the evolution of the metallurgical notch. The inflexion point of the cyclic strength increased for about $50 \%$ compared to the seams brazed with a wire rate of $3.2 \mathrm{~m} / \mathrm{min}$, Fig. 15 . The fatigue strength is in the same scatter band, although the low energy brazed samples are slightly higher. Disadvantageous when using low energy input is that the scattering of the fatigue strength increases. 


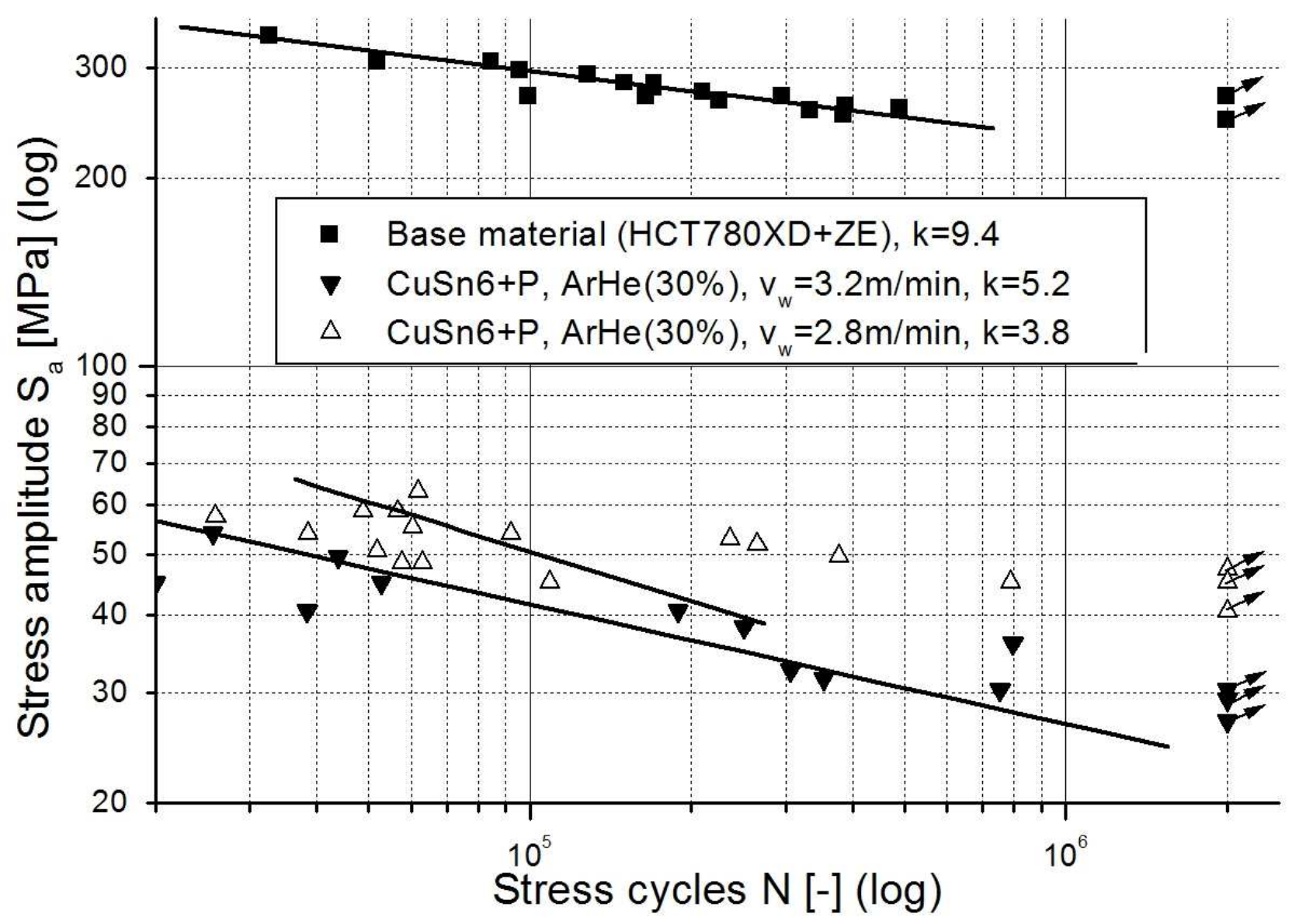

Fig. 15: S-N-curve - comparison of heat input, HCT780XD, $\mathrm{R}=0.1$, unilateral

Influence of brazing filler. Besides the modification of the macro geometry by variation of the guidance of the process control, studies on the influence of different brazing fillers were carried out. For the investigations common copper-based fillers were chosen, cp. Table 4, with different properties in respect of:

- mechanical resistance (cyclic and static)

- viscosity

- wetting properties

- melting points

These characteristics are used to investigate and improve the cyclic strength of the junction. For comparison all brazed-fillers were assimilated at the lowest possible rate of the wire feeder at which a reliable process control can be realised. As expected the tensile strength of the brazed seams are lined up in the same way as the strength of their brazing filler. For the cyclic strength a different result was found, Fig. 16. The brazing filler with the lowest mechanical resistance $(\mathrm{CuSn} 6+\mathrm{P})$ has the highest fatigue strength. It is up to $30 \%$ higher than the compared lines of fatigue strength.

Additionally the statistical scattering evolves likewise the cyclic strength. The CuSn6+P filler is barely spreading whereas the results of $\mathrm{CuAl} 7$ - and $\mathrm{CuSi3Mn1-filler}$ are scattered partly so much that it is difficult to determine a regression line at all, especially for the CuAl7-filler. 


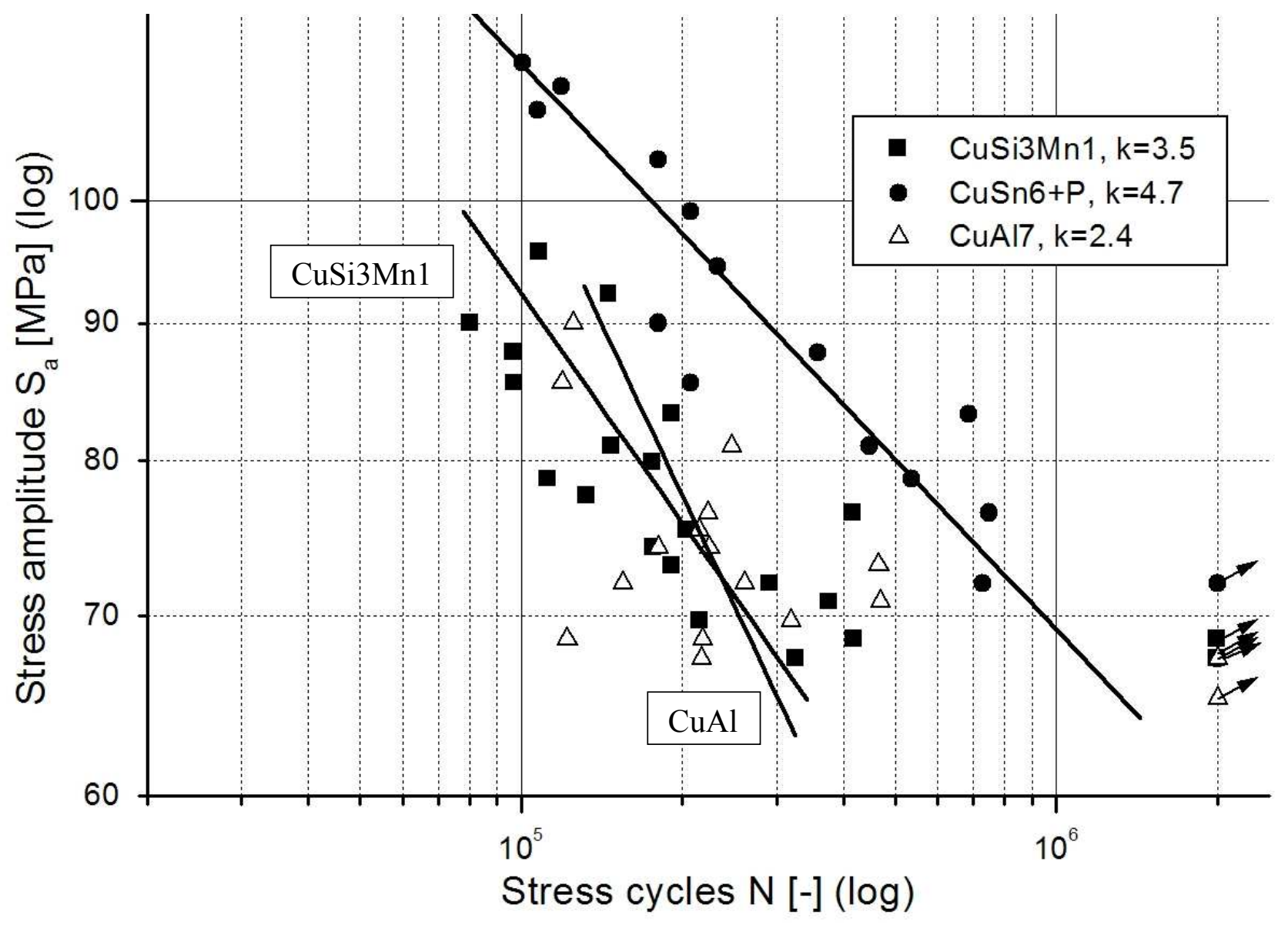

Fig. 16: S-N-curve - comparison of brazing fillers, HCT780XD, R=0.1, bilateral

The comparison of different filler materials also approves the result of the influence of the heat exposure. Those samples brazed with higher strengthened CuAl7-filler also need more energy in the process, cp. Fig. 17b, as it can be measured by the extended development of the HAZ. As a consequence the edge of the upper sheet is molten, but the seam for itself is without remarkable failures. The strength of the filler accompanies a lower absorption which results in the wide spreading of the alternated samples. Additionally the processing of $\mathrm{CuAl} 7$ is more complex because the arc process is more instable and it has a higher addiction to spattering. It is also shown in Fig. 17a, that the CuSn6+P filler has seam imperfections because of the low process heat. These voids do not lead to a noticeable reduce of the cyclic load. Another advantage of the manufacturing of $\mathrm{CuSn} 6+\mathrm{P}-$ filler is that the reduced heat input is measurable at the rear side of the brazed sheets, cp. Fig. 18. Partly a surface-melting is detectable whereas at the rear side of the CuSi3Mn1-filler the zinc surface is partly burnt. This fact results in an inefficient corrosion protection of the rear side of brazed sheets; in that case they need to be post-treated with a surface protection. 


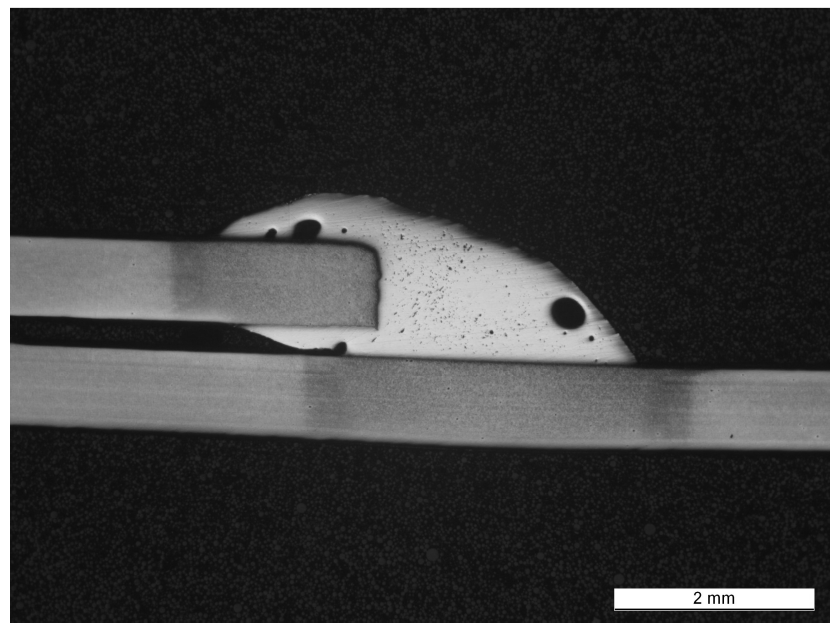

CuSn6+P-brazed seam

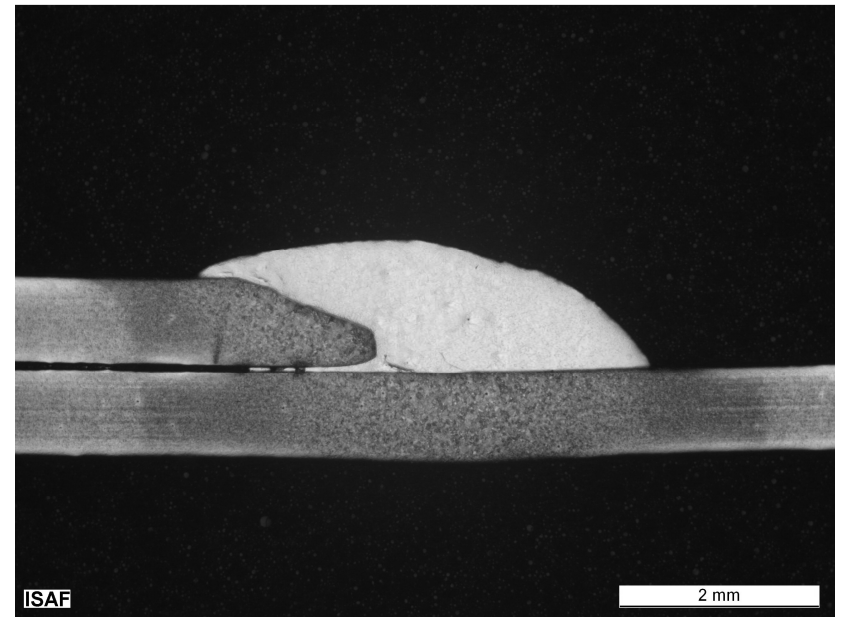

CuAl7-brazed seam

Fig. 17: Brazed seams with different fillers; scale: $2 \mathrm{~mm}$

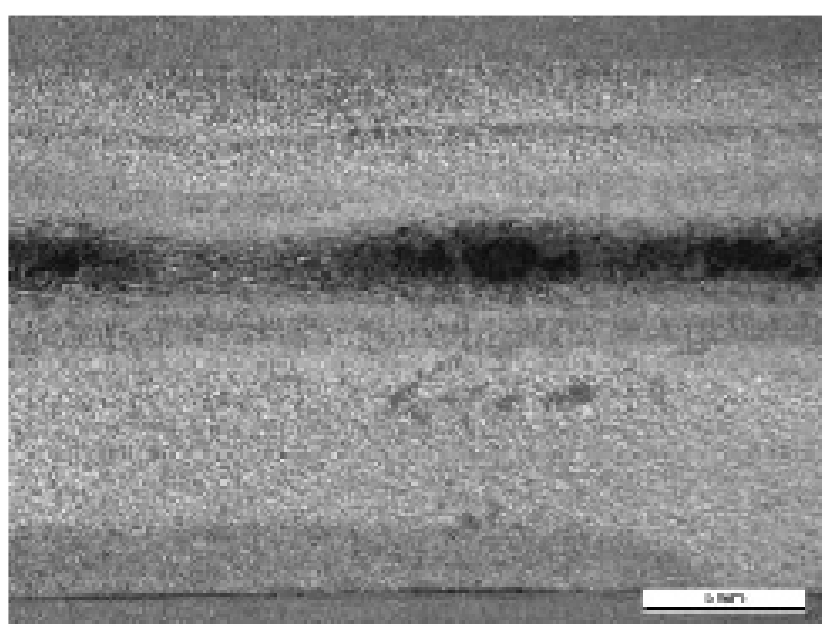

Rear side of sheet CuSi3Mn1

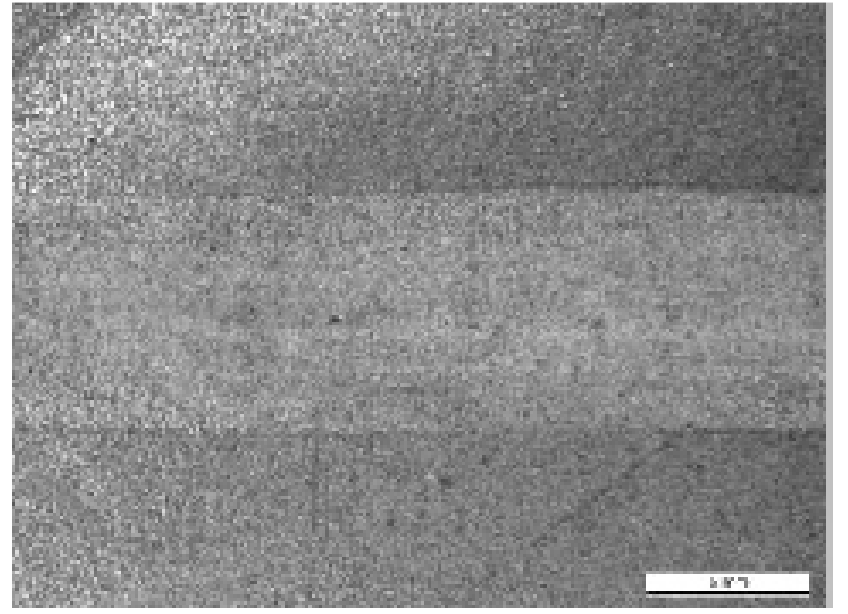

Rear side of sheet $\mathrm{CuSn} 6+\mathrm{P}$

Fig. 18: Rear side of the sheets brazed with different heat input because of the application of different filler materials; scale: $2 \mathrm{~mm}$

Influence of differing arc-brazing processes. As shown beforehand it is necessary especially for the conservation of local properties of high strength steel sheets to use a low heat joining process. Another method investigated in this coherence is the Plasmatron process. This process enables an autonomous control of the wire feeder and the heat of the process. Due to the special construction of the torch this process also enables to locally focus the plasma. The first results of the process are already promising. At the beginning of the Plasmatron testings the following parameters shown in Table 7 were used. These parameters cause a seam which has no imperfections and a narrow width, see Fig. 19. Additionally the Plasmatron-brazed seam is not scaled compared to the CMT-joints. 
Table 7: Parameters used for Plasmatron-brazing

\begin{tabular}{|c|c|c|c|}
\hline filler & rate of wire feeder & current & voltage \\
\hline $\begin{array}{c}\text { CuSi3Mn1 } \\
\text { (diameter: } 1.0)\end{array}$ & $4.0 \mathrm{~m} / \mathrm{min}$ & $87 \mathrm{~A}$ & $12.7 \mathrm{~V}$ \\
\hline
\end{tabular}

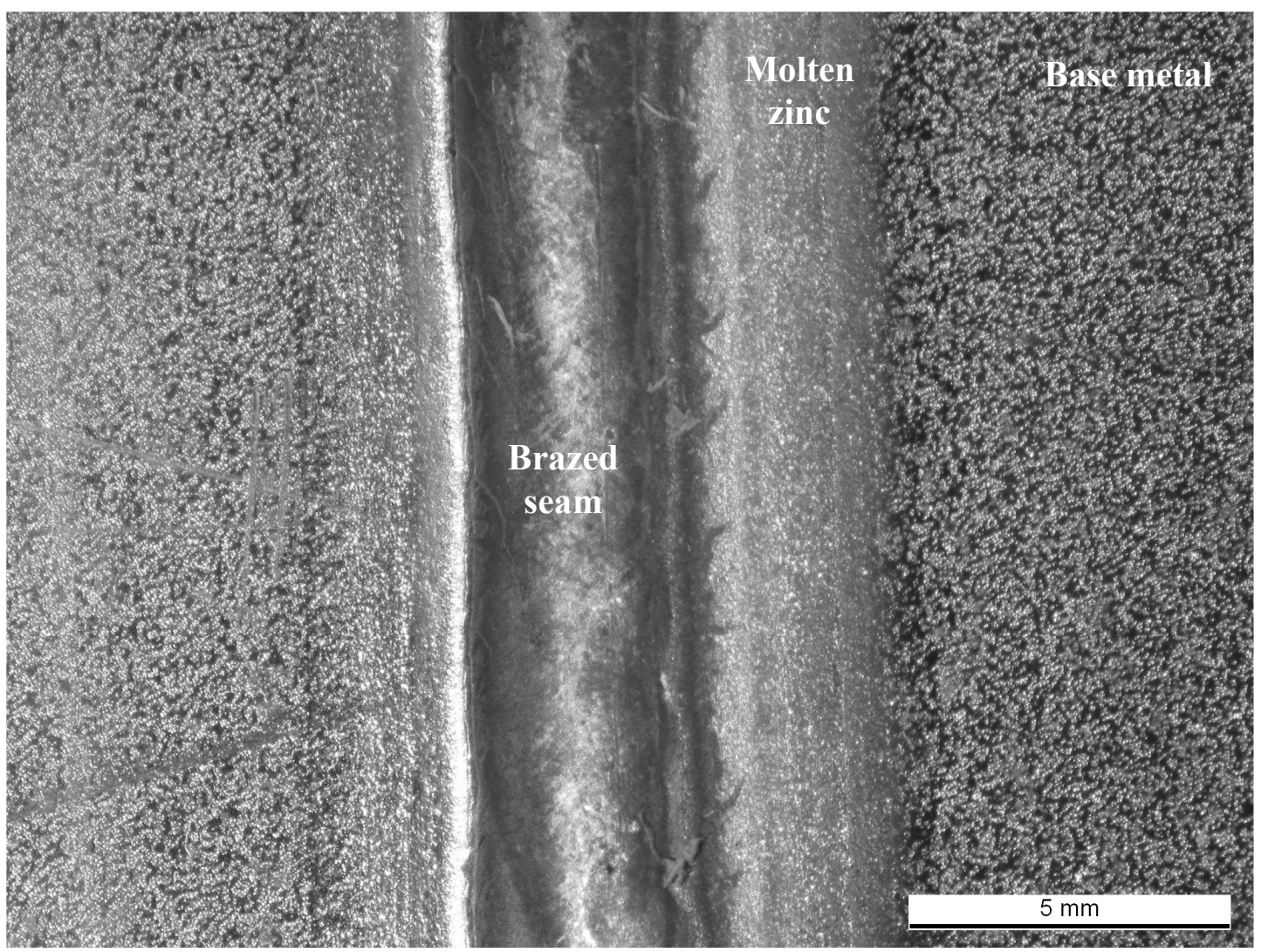

Fig. 19: Top view on a Plasmatron brazed joint; scale: $5 \mathrm{~mm}$

Further investigations were done on the effect of a copper-bar used to reduce the heat input and a thicker diameter of wire $(1.6 \mathrm{~mm})$. The usage of a copper bar leads to a faster cooling of the base material which resulted in a higher detraction because of martensite evolution and an increase of hardness. The investigations showed that this method of brazing is not advantageous if increased fatigue strength should be achieved. The studies on the thicker wire diameter showed up similar difficulties. The heat needed for melting the wire affects the base material and the increased amount of filler material yields up to a notch with a large-scaled contact angle and a high seam volume, cp. Fig. 20b, compared to the brazed seam with a wire diameter of $1.0 \mathrm{~mm}$, cp. Fig. 20a. 


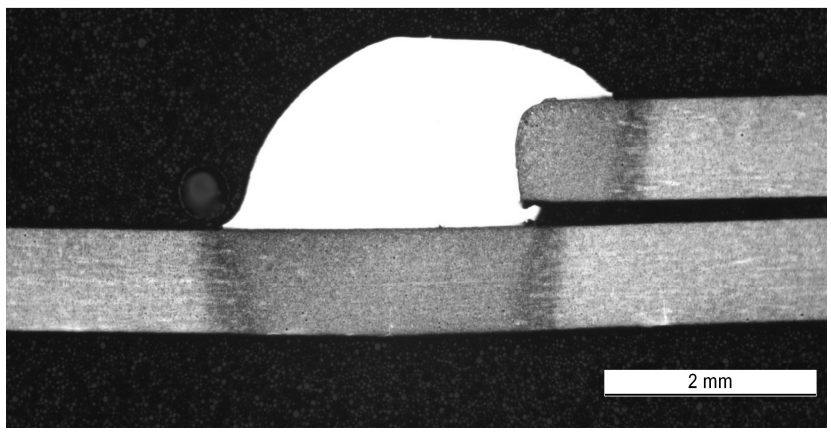

a) Brazed seam, CuSi3Mn1 (1.6 mm)

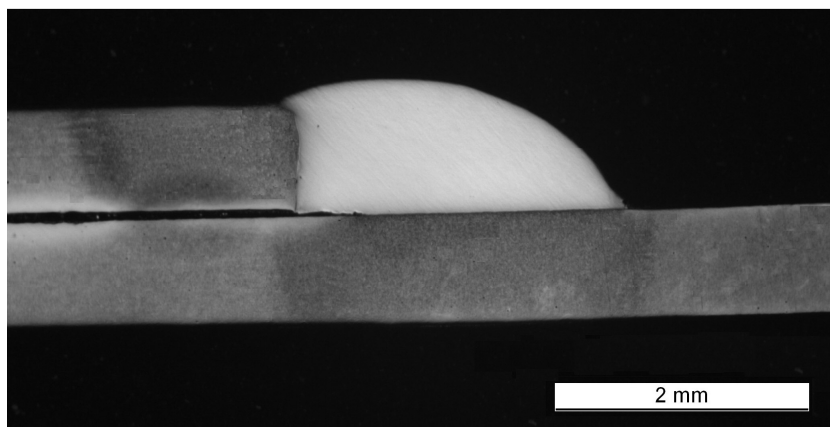

b) Brazed seam, CuSi3Mn1 (1.0 mm)

Fig. 20: Plasmatron brazed joints; scale: $2 \mathrm{~mm}$

The comparison of the fatigue strength of the Plasmatron-process with the base material is shown in Fig. 21. Although the specimen of the Plasmatron process had been brazed with the CuSi3Mn1filler, their stress amplitude is up to $20 \%$ higher compared to studies on samples manufactured with the CMT-process. The processing of $\mathrm{CuSn} 6+\mathrm{P}$ that has been used for CMT will be part of further investigations and promises a reducing of the heat input and therefore an increased fatigue strength, as shown in previous results. The scattering as well as the slope of the results are comparable to the results of the CMT-process.

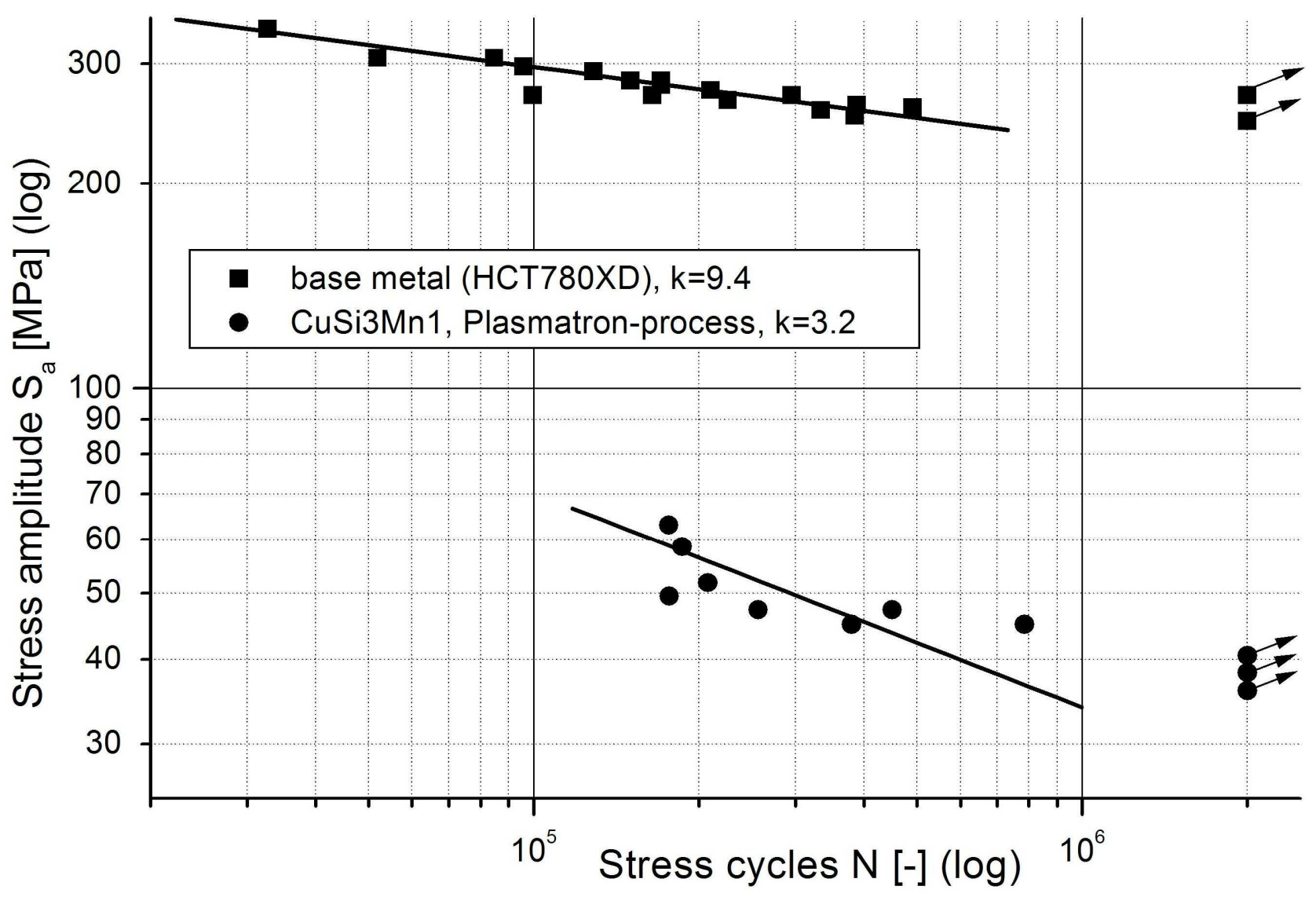

Fig. 21: S-N-curve - comparison of Plasmatron process with base material, unilateral, HCT780XD, $\mathrm{R}=0.1$

Additionally the Plasmatron-process demonstrated that at unilateral brazed joints, as investigated by this process, a build up of the brazing alloy is necessary, although this perception is contradictory to common qualification methods. But these base on static strength investigations in which a build up 
of the seam is classified as imperfection $[15,16]$. In Fig. 22 an example of a stress simulation of unilateral Plasmatron brazed joints is shown. The seam with the build up has the highest stress concentrations equally distributed on the upper sheet and the boundary between filler and base material of the lower sheet. Additionally the cross-section shows, that the stress peaks are not at the same line but offset. Therefore the flux of force is favourable. In the second picture the stress concentration of a seam without build up is shown, which clarifies, that the stress concentration is mainly at the root concavity and the stress peaks of the root concavity and the upper sheet are on the same line. This fact leads to a multi-axial load during cyclic testings resulting in an early shearing of the brazed alloy and the upper sheet.
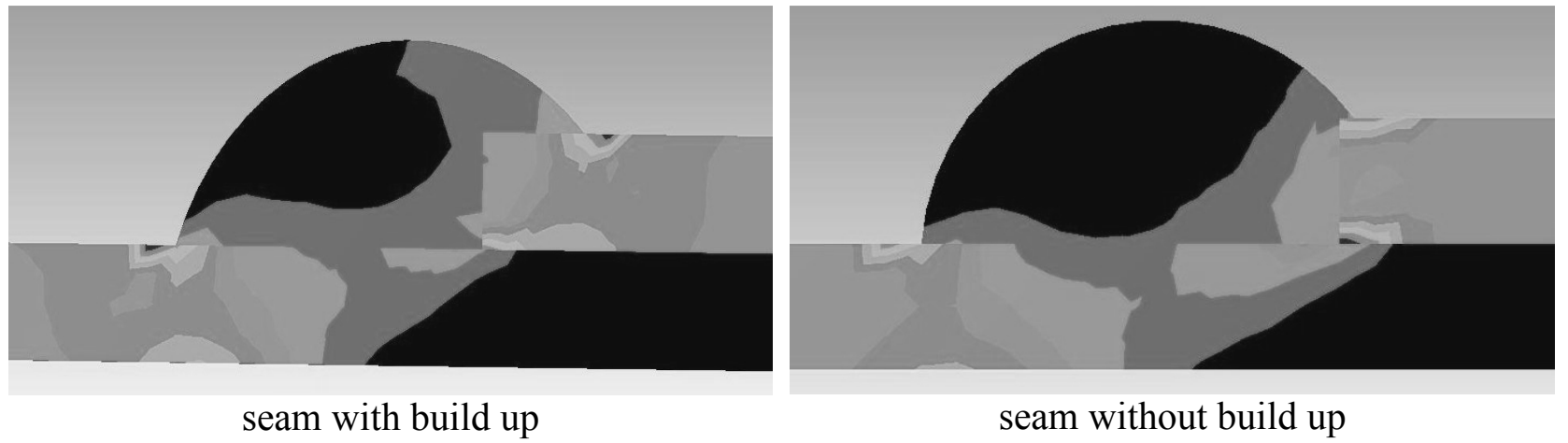

Fig. 22: Stress simulation of Plasmatron brazing

Influence of thermal-treatment. Another advantage of the Plasmatron-process is shown in the following part. It is possible to accomplish a serial heat treatment by a plasma treatment without additional brazing filler and a desirable reduced heat input.

The thermal post-treatment of brazed seams makes up a further possibility for influencing the seam geometry. Due to remelting of the brazing filler by the application of thermal seam treatment a reduced wetting angle between the filler and the bottom sheets develops, leading to a change of the geometrical notch, cp. Fig. 23. As a result the stress concentration is decreased. Coincidental by remelting, the metallurgical notch at the upper sheet is thermally affected and strengthened. Therefore the static strength of the heat treated seam is increased for about one fourth without an increased hardness, cp. Fig. 24.

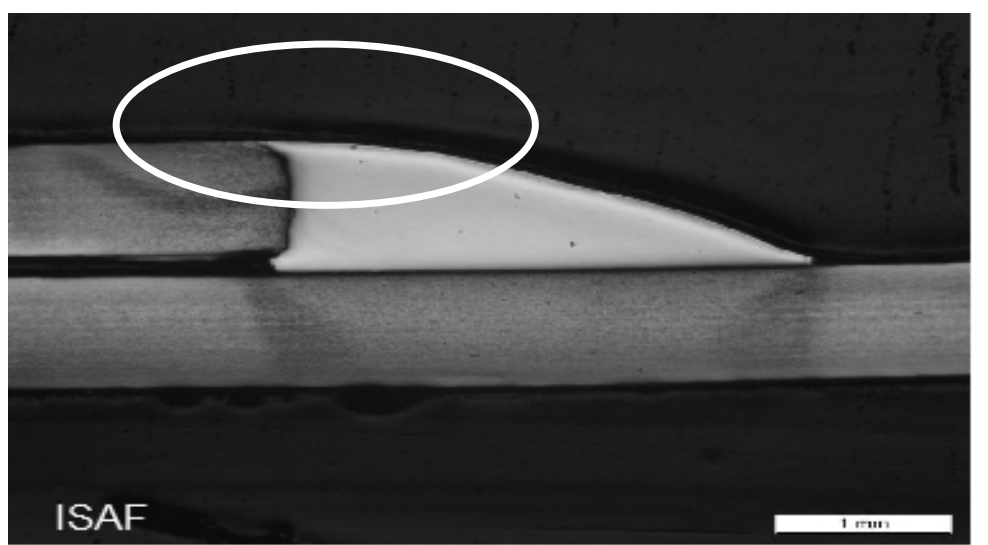

Fig. 23: Plasmatron brazed unilateral joint with serial thermal treatment (marked up); movement speed $1 \mathrm{~m} / \mathrm{min}$; current $20 \mathrm{~A}$; scale: $1 \mathrm{~mm}$ 


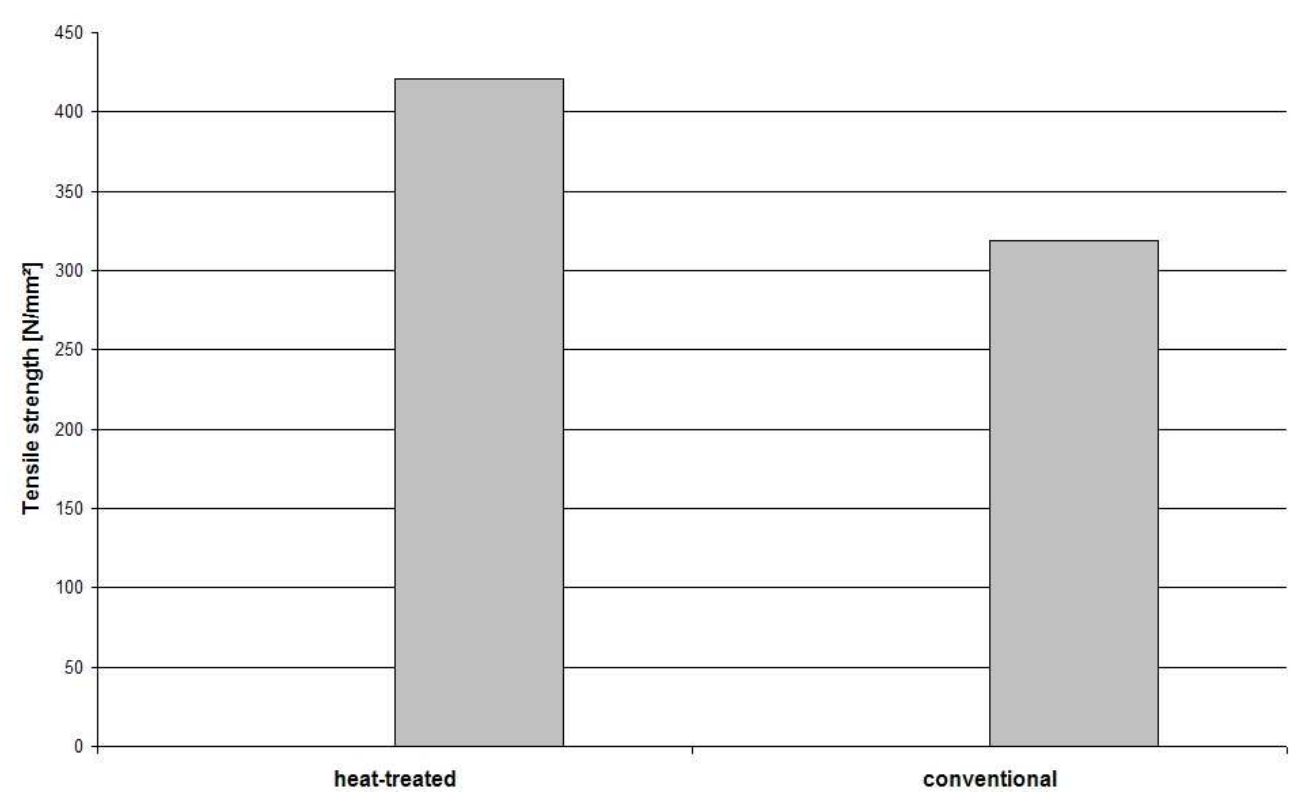

Fig. 24: Tensile strength of conventional and heat-treated brazed seams

Influence of differing post-treatments. Another method for increasing the fatigue strength of brazed seams is mechanical post-treatment. For manufacturing of bilateral brazed joints of the CMT-process (brazing filler: CuSn6 $+\mathrm{P}, \mathrm{v}_{\mathrm{w}}=2.8 \mathrm{~m} / \mathrm{min}$ ) have been used. The intention of the posttreatment of the seam is to locally induce compressive residual stresses and to influence the geometrical notch in order to achieve an enhancement of cyclic strength.

For the post-treatment the shot-peening and the intensive hammering process have been used. The specimens were shot-peened using a gravity induction system GRAVI (OSK Kiefer GmbH), and SCCW14 (spherical conditioned cut wire) with an average size of $350 \mu \mathrm{m}$. Peening was performed for 30 and $60 \mathrm{~s}$ relating on a conditioning length of $145 \mathrm{~mm}$ per side at an air pressure of 1, 3 and 5 bar. The intensive hammering was done by pneumatic impact treatment (PIT) by PITec $\mathrm{GmbH}$. To achieve an overlapping of at least $100 \%$ the specimens were accomplished with a pressure of 4 bar and a frequency of $90 \mathrm{~Hz}$.

The results of the shot-peening treatments are shown in Fig. 25. As can be seen there is no increased strength within the low cycle fatigue. At a jet pressure of 1 bar the lowest fatigue strength is achieved. Contrary compared to the untreated brazing connection even an attenuation of the joint occurs. This result can be traced back on the micro-notches additionally inserted by the treatment. Starting at a jet pressure of 3 bar the changing point to the endurance level is increased (endurance level has not been detected). At this air-pressure adequate compressive stresses are inserted to the brazed joint, for increasing the fatigue strength for about $10 \%$. By using a pressure of 5 bars and a exposure time of $60 \mathrm{~s}$ the cyclic strength can even be increased for further $10 \%$. At these preexaminations 5 bars has been the upper limit for shot-peening, because at this point an unacceptable high deformation of the steel sheets occurred. In the future there need to be more studies on the different influences of shot-peening on the fatigue properties need to be carried out. 


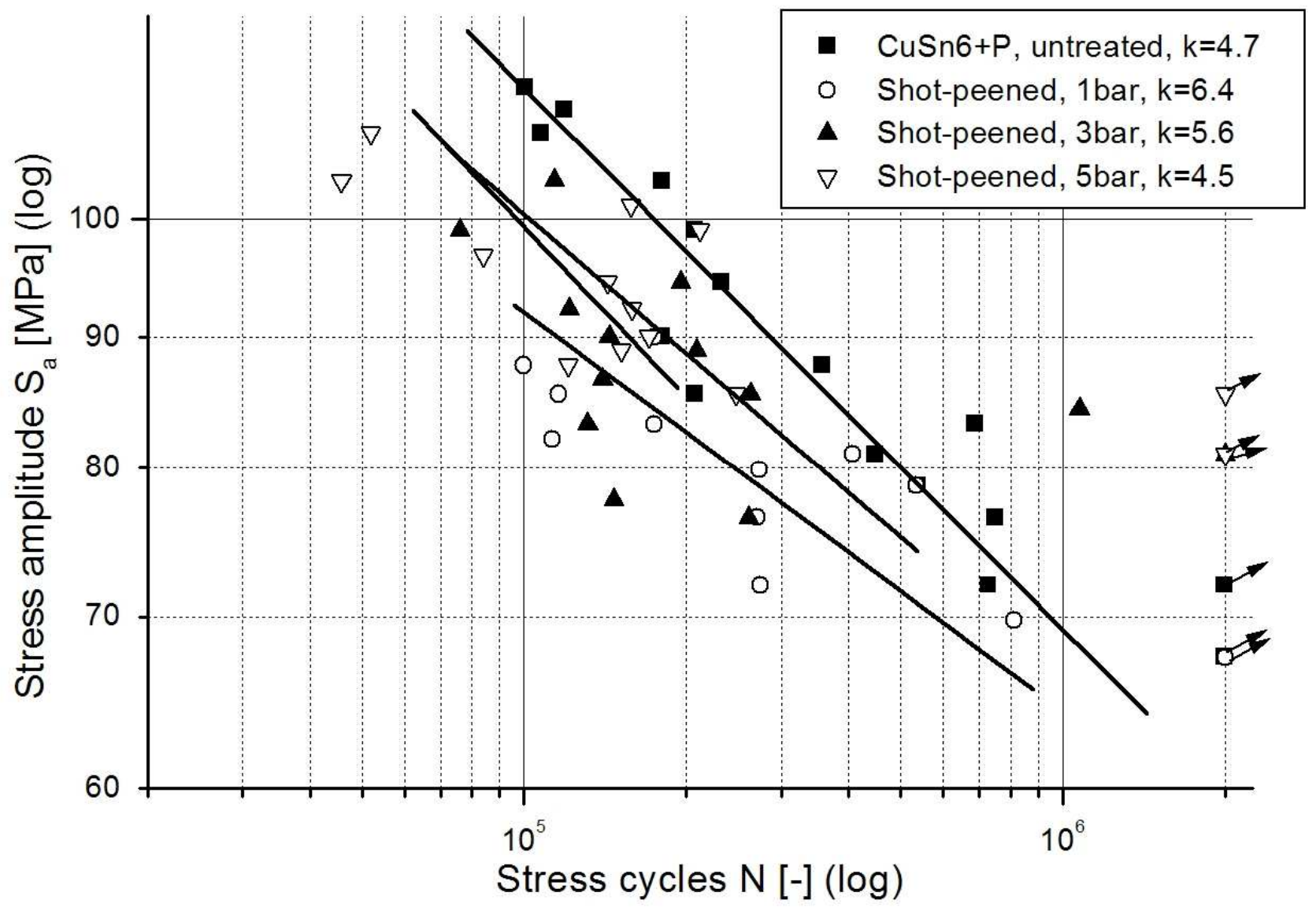

Fig. 25: S-N-curve - different shot-penning post treatments, HCT780XD, CuSn6 $+\mathrm{P}, \mathrm{R}=0.1$, bilateral, $\mathrm{t}=30 \mathrm{~s}$ at 1 and $3 \mathrm{bar}, \mathrm{t}=60 \mathrm{~s}$ at 5 bar

In comparison to shot-peening by intensive hammering a locally more limited treatment is achieved, see Fig. 26. The conditioning is just located at the rim of the seam, exactly into the notch base, and as a consequence harming of too many notches is avoided. Only the boundary of brazing filler and base material at the lower sheet is treated, therefore the affect on the zinc-coating is limited. It was found, that in this case for the first time the braze filler and process characteristics are responsible for the cyclic resistance, cp. Fig. 27.

Due to the post treatments a considerable increase of the fatigue strength of arc brazed high strength steel sheets could be achieved. 


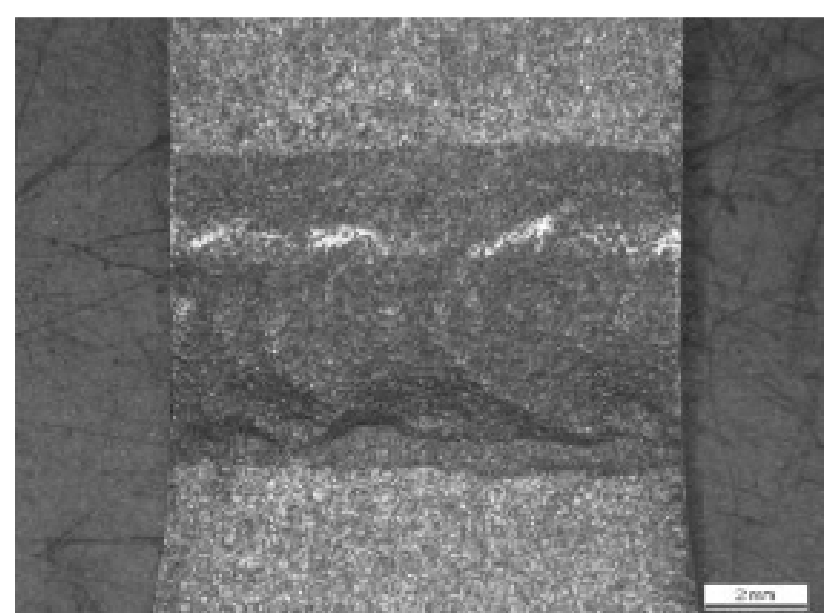

a) Shot-peened seam

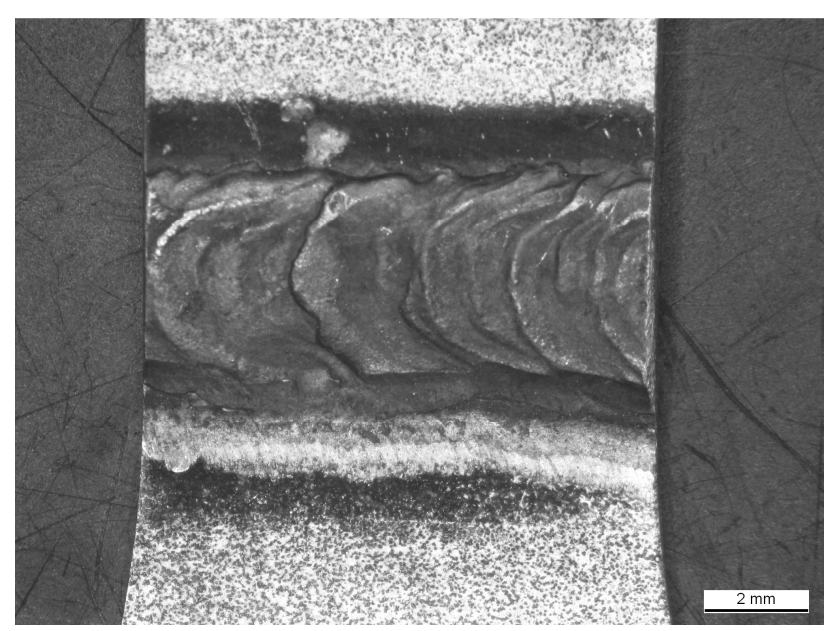

b) Intensive hammered seam

Fig. 26: Comparison of post treated seams; scale: $2 \mathrm{~mm}$

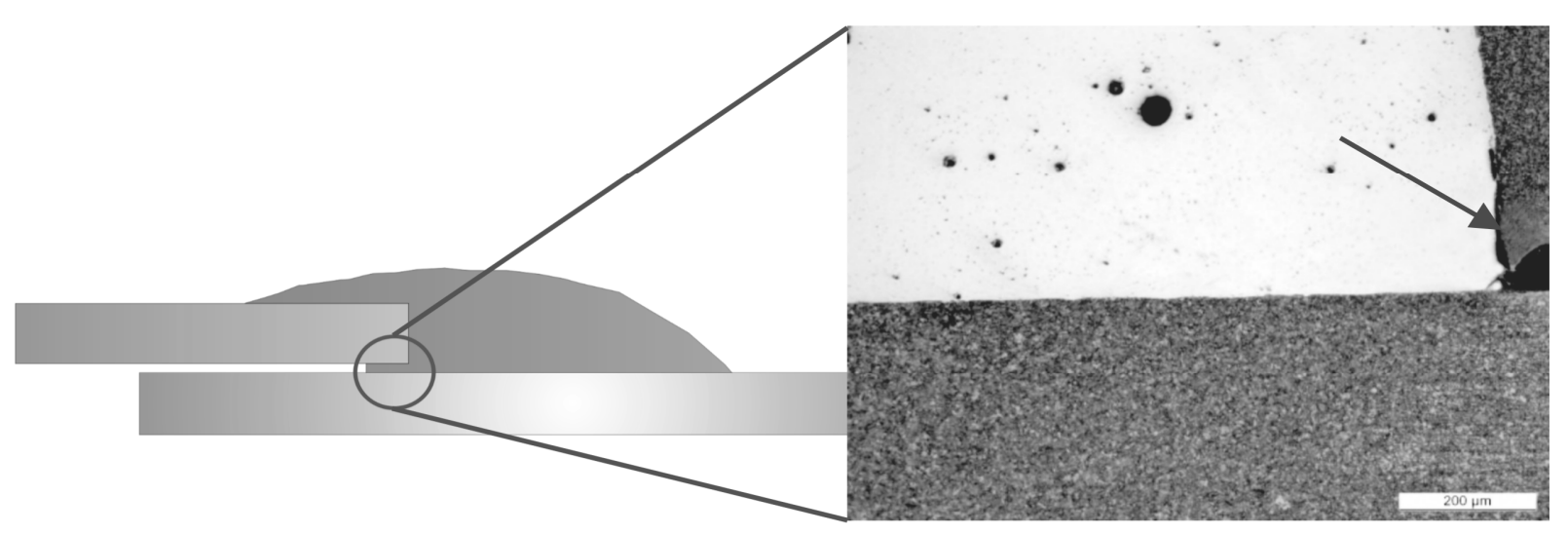

Fig. 27: Failure locations under cyclic loading, intensive hammered seam; scale: $200 \mu \mathrm{m}$

The influence of the intensive-hammering process on the fatigue strength in comparison to the shotpeening is shown in Fig. 28. The hammered specimen have increased bearable stress cycles of about $10 \%$ and compared to the untreated brazed-joints even an increase of $20 \%$ is achieved. These results are due to the more localised treatment and the better coverage. This is also shown by the scattering as well as the slope of the regression lines. 


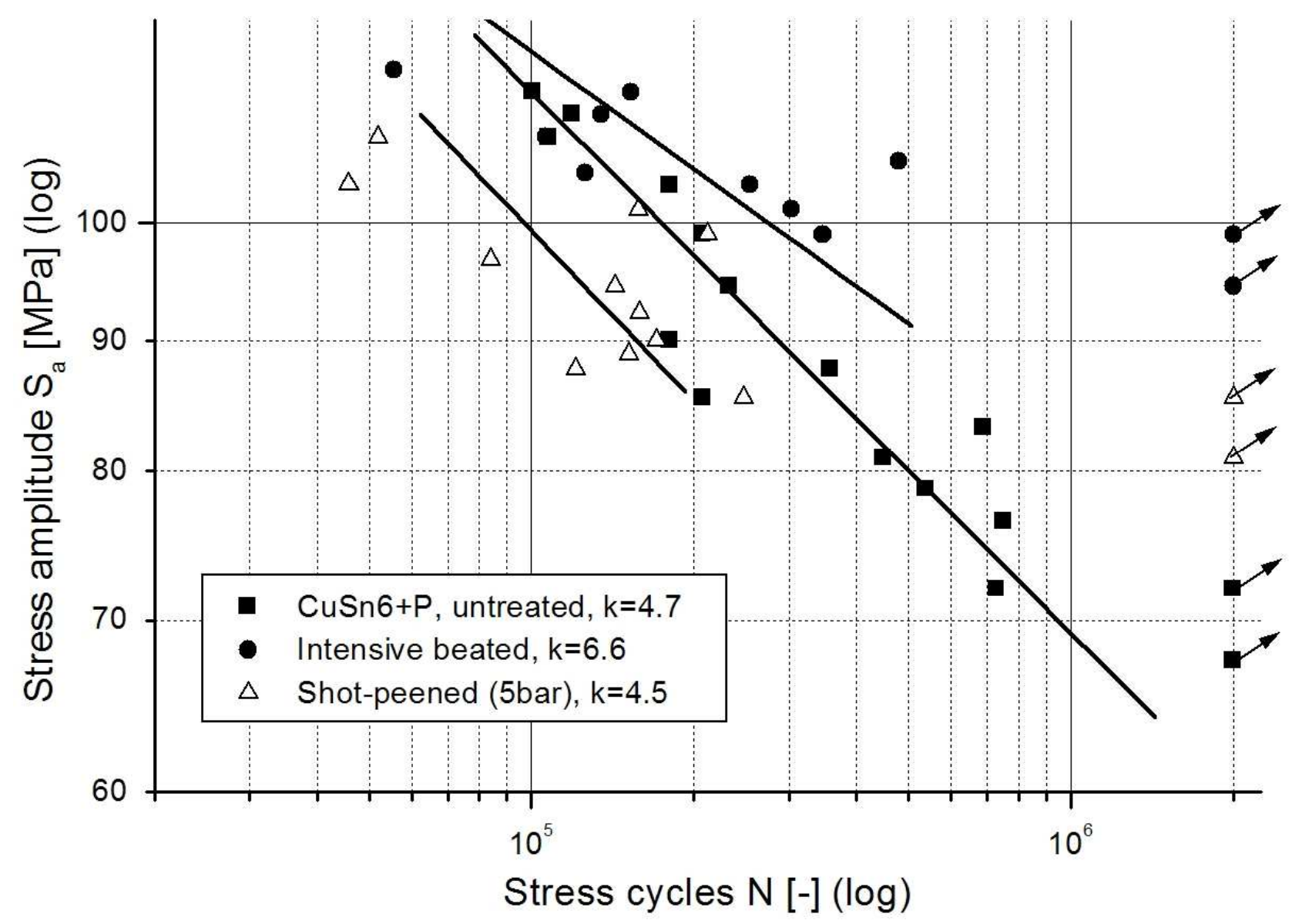

Fig. 28: S-N-curve - comparison of post treated seams, HCT780XD, CuSn6 $+\mathrm{P}, \mathrm{R}=0.1$, bilateral

Influence on failure locations under cyclic load. It was possible to compile differing failure locations at brazed joints under cyclic load, which are relevant for the quality of the joints, cp. Fig. 29. The failure locations can be ascribed on different causes of malfunction and thus needing a specific property adapted strategy of manufacturing.

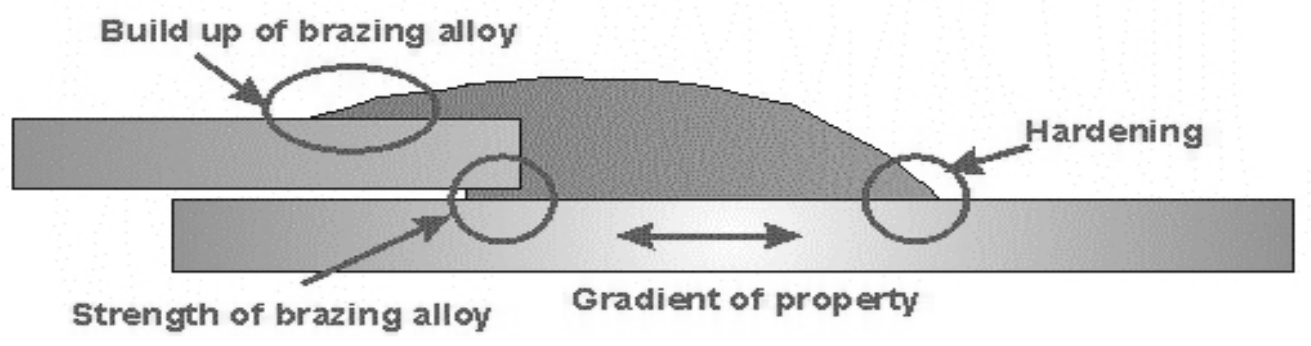

Fig. 29: Failure locations under cyclic load

The first failure location, already described beforehand, occurs in large parts at the knot of the metallurgical and geometrical notch as well as the change of stiffness. This failure location can be ascribed to local hardening as well as softening of the base material by means of the metallurgical notch. At this for cyclic loading critical region the coarse grained zone, the fine-grained region, and the unaffected material is closely located. Additionally a local decrease of hardness combined with the cross-over of the metallurgical and geometrical notch exists. This weakens the mechanical resistance of the joint. Further on the preservation of the property gradient is necessary at this point for the usage of locally adjusted property structures. 
The second failure location can be reflected to the mechanical resistance and ductility of the brazed filler and the connection to the base material. For increasing the mechanical resistance of the joint a high strength filler material is needed with appropriate ability of gap-filling as also demanded in [17]. Unfortunately nowadays these diverging properties to increase the fatigue strength cannot be achieved by a single brazing filler.

The last failure location has been detected at the Plasmatron-process. It was found that there need to be a build up of the brazing alloy at the upper steel sheet to accomplish appropriate fatigue strength.

\section{Summary}

The identification of different influences on the metallurgical and geometrical notch distinguish the intention to use low-heat-processes for joining locally strengthened materials especially under cyclic load. But the results also show a high potential for further investigations. Because of the application of low-heat arc-brazing processes, mechanical properties of the HCT600XD could be preserved largely [18], due to a locally narrow limited heat affected zone (HAZ) in the upper and lower sheets in which martensite evolution and other impacts of the structure occurs. The HAZ in the lower sheet is only spreading in the same scale as the brazed connection length. First comparative studies showed that the fatigue strength of bilateral brazed joints is up to $40 \%$ higher than laser-welded seams without filler material. Additionally they have a stress amplitude which has a five times higher survival probability of the brazed seams [4].

Furthermore the results show that a variation of the seam geometry is only useful in order to increase the fatigue strength if the heat input in the material during the brazing process is kept at a quite low level. The brazed joint with the meanest geometrical notch has been the weaved seam (weaving by torch). It has a large-scaled connection length and a small connection angle. Unfortunately the input of energy was too high. Locally the base material has been molten and further on the process heat led to deformation and a highly affected structure. Because of hardening effects the cyclic strength of the joints was reduced. The energy input also caused severe disturbance of the mechanical-technological properties of the specimens with multi-layered and TIG remelted joints. The best results for statical and cyclic strength were achieved at bilateral brazed fillets with overlapping and with reduced process-heat-input. It follows from the above that besides the geometrical notch also the metallurgical notch has a high influence on fatigue strength.

This thesis is substantiated by investigations on the influence of the shielding gas. By application of differing types of shielding gas the heat input as well as the formation of the seam could be influenced. Furthermore the results confirm that optical and/or metallographic deficient brazed seams, cp. [15, 16], mostly had a better strength under cyclic loading compared to seams confirming the standard. No influence of the porosity of the brazed joints on the cyclic strength could be detected. As a consequence joints brazed at the lowest limit of the processing window partly have a higher porosity and an inappropriate connection angle but still exhibit good or even better fatigue strengths. A further evidence for this is that mechanically reduced seam-geometries also do not have a remarkable influence on the fatigue strength. In both studies the cross section of the samples were reduced. Therefore the crucial factor for the cyclic strength of the joints are the connection of the filler and the base material, the type of loading (overlapping, multi-axial) and the structure of the HAZ.

It is not possible to evaluate manufacturing parameters for application under cyclic loading only by quasi-static testings. For this reason continuative studies were carried out by brazing with the lowest possible heat-input in the base material of the high strengthened steel sheets still enabling a reliable and stable process control [19]. 
The investigations on the influence of brazing fillers on the fatigue strength resulted in the perception, that it is possible to change the geometrical notch by using different fillers and exploit their properties [20]. It has been exposed that the application of higher strengthened brazing alloys do not lead to an increase of the fatigue strength, which can be related to their problems during manufacturing (process stability, connection to base material) and their decreased damping features (ductility). Further on the application of $\mathrm{CuSn} 6+\mathrm{P}$ is advantageous because the required heat input is low and compared to the common used cheaper $\mathrm{CuSi3Mn1-filler} \mathrm{following} \mathrm{varnish} \mathrm{processes} \mathrm{are}$ not interfered [21].

The first investigations on the influence of differing arc-brazing processes showed the advantage of the autonomous control of wire-rate as well as the process-heat. Contrary to the MA-brazed seam the plasma brazed one is not scaled. Among others this fact leads to increased fatigue strength. Due to the Plasmatron-process the heat affection of the micro structure is only locally affected compared to common plasma-brazing. These facts rised up to an increase of the fatigue strength of the joints of about $20 \%$ compared to the seam from the CMT-process, although the applied filler material differed. The one used at plasma-brazing was even the worse one which has been shown in the results of the effect of filler material on the cyclic strength.

Another advantage of the Plasmatron-process is that a serial heat treatment of the seam can be realised. Due to this method the geometrical notch as well as the wetting angle can be decreased. This technique shows already an increasing of the tensile strength of about $25 \%$, but further studies on the effect of the fatigue strength are needed. These results are promising because the microstructure of the base material after the heat treatment is hardly affected and therefore this should not effect the metallurgical notch.

Another kind of post treatment is to subject the brazed seam by a mechanical treatment. These procedures are commonly used for welded seams [22, 23], but so far an adaptation on brazed seams has not taken place. The results of the shot-peening as well as the intensive-hammering are promising. Increased fatigue strength is realised, although the samples break early the fatigue-tested specimen without rupture are at higher amplitude. By the hammering-process the cyclic strength is about $20 \%$ higher compared to untreated specimens.

It could be distinguished that the treatments have to be extended to coverage of at least $100 \%$, otherwise the induced micro-notches cause an early break, as a consequence of the notch-sensitive base material. The shot-peening compared to the hammering is not locally limited and the edge of the notch which should be treated has partly not been influenced.

Advantageous of the post-treatment is the possibility to displace the failure location to the rootconcavity. Due to this displacement the brazing filler as well as the process characteristics are responsible for the cyclic strength of the samples for the first time.

Based on these studies a developing of a manufacturing-concept for arc-brazed, high strength structure of locally adapted materials is needed, because so far the investigations were only done using plain-sheet metals. Further on there need to be studies not only on the static and cyclic strength of brazed joints as well as on the dynamic strength. As the results show the effects for high static strength differ to the demand of application under cyclic load. As a consequence there is a high probability of differing demands under dynamic application.

For the brazing-concept it is necessary to investigate the endurance strength and to develop a fatigue life calculation concept, which is needed for dimensioning. 


\section{Acknowledgement}

The authors would like to thank the DFG (German Research Foundation) for financial support within the program SFB 675 "High-strength structures". Furthermore the Salzgitter Mannesmann Forschung is gratefully acknowledged for providing the experimental steel for this investigation. In addition we would like to thank the Institute of Plant Engineering and Fatigue Analysis of Clausthal University of Technology for their advice and assistance concerning fatigue testings.

\section{References}

[1] F. Behr: Die ultraleichte Stahlkarosse - neue Produkte und Fertigungsverfahren / The ultra light steel auto body - new products and processes, Materialwissenschaft und Werkstofftechnik, 30 (1999), 11, pp. 669-677

[2] C. Darling: Brazing: An important joining option, Welding Journal 88 (2009), 4, pp. 41-43

[3] A.H. Wirth, H. Laukant, et al.: Laser brazing of high strength steels, ICALEO, Laser Materials Processing Conference, 26 (2007), pp. 570-576

[4] A.R. Schram, R. Masendorf, T. Medhurst, H. Wiche: Manufacturing and fatigue strength of brazed locally hardened structures, Steel Research International, 79 (2008), 3, pp. 219-224

[5] R. Song, J.G. Schroth, et al.: Copper brazing response of some advanced high strength steel grades, Journal of Materials Processing Technology, 09 (2009), 1, pp. 70-76

[6] W. Fluegge, A. Kröff: ScaLight - Neue Fertigungstechniken mit Stahl, Tagungsband EU Forschungsgemeinschaft für Blechverarbeitung e.V., 29 (2008), pp. 145-155

[7] U. Reisgen, U. Dilthey, A. Sevim: Als Fügeverfahren geeignet - MSG-Löten höchstfester Bleche im einseitigen Überlappsto $\beta$, Stahl, (2009), 1, pp. 20-22

[8] V. Wesling, A. Schram, A. Ait-Mekideche: Plasmalöten oberflächenveredelter Feinbleche, Praktiker, 55 (2003), 7, pp. 196-200

[9] A. Helmich: Untersuchungen zum wärmearmen Fügen von Feinblech mit Kupfer Basis-Loten, 2002, Diss.: TU Clausthal

[10]M. Kueppers, H. Kaufmann, et al.: Verbesserung der Schwingfestigkeit von Schweiß- und Lötverbindungen durch prozessoptimierte Gestaltung der Nahtgeometrie, Schweißen \& Schneiden, 61 (2009), 4, pp. 192-203

[11]A. Millinger: Der CMT Prozess- eine Revolution in der Fügetechnik, recitation Fronius $01 / 2005$

[12] Inocon [online] 2010 (15.01.2010), www.inocon.at

[13]J.M. Hadianfard: Low cycle fatigue behaviour and failure mechanism of a dual-phase steel, Materials Science and Engineering, A 499 (2009), 1-2, pp. 493-499

[14]S. Oliver, T.B. Jones: Dual phase versus TRIP strip steels: Microstructural changes as a consequence of quasi-static and dynamic tensile testing, Materials Characterization, 58 (2007), 4, pp. 390-400

[15]N.N.: DVS-Merkblatt 0938-1, (2001)

[16]N.N.: DVS-Merkblatt 0938-2, (2005) 
[17]U. Reisgen, L. Stein, M. Sevim: MSG-Löten mit Fülldrähten zur Steigerung der Festigkeitseigenschaften am Beispiel höherfester Stahlwerkstoff, Schweißen \& Schneiden, 61 (2009), 8, pp. 401-409

[18]V. Wesling, A. Schram, M. Kessler: Wärmearmes Fügen - Fertigung lokal verfestigter Strukturen, 6. Industriekolloquium SFB 675, (2007), pp. 83-88

[19]V. Wesling, A. Schram, M. Kessler: Wärmearmes Fügen - Eigenschaften schutzgasgelöteter Feinbleche unter statischer und zyklischer Belastung, 7. Industriekolloquium SFB 675, (2009), pp. 85-91

[20] V. Wesling, A. Schram, M. Kessler: Festigkeit von wärmearm gefügten Verbindungen unter zyklischer Belastung, Schweißen \& Schneiden, 61 (2009), 11, pp. 658-662

[21]O. Paetzold: Auswirkungen von Lötnähten an Automobilkarossen auf das Ergebnis nachfolgender Beschichtungsprozesse / Impacts of brazing seams at car bodies on the result of following coating processes, DVS-Berichte, 250 (2008), pp. 430-433

[22]T. Nitschke-Pagel, K. Dilger: An die Erfordernisse angepasst. Nachbehandlungsverfahren zur Verbesserung der Schwingfestigkeit von Schweißverbindungen, Stahl, (2008), 4, pp. $40-44$

[23]T. Ummenhofer, S. Herion, I. Weich: Schweißnahtnachbehandlung mit höherfrequenten Hämmerverfahren - Ermüdungsfestigkeit, Qualitätssicherung, Bemessung / Postweld treatment by high frequency hammer peening methods - Fatigue resistance, quality control, design, Stahlbau, 78 (2009), 9, pp. 605-612 